\author{
UNIVERSIDADE DE SÃO PAULO \\ ESCOLA DE ENFERMAGEM DE RIBEIRÃO PRETO \\ DEPARTAMENTO DE ENFERMAGEM GERAL ESPECIALIZADA
}

\title{
ESTUDO DA OCORRÊNCIA DE ACIDENTES ENTRE TRABALHADORES DE UMA INDÚSTRIA FRIGORÍFICA DO ESTADO DE SÃO PAULO
}

Marília Marcondes Campoamor

Ribeirão Preto

2006 


\author{
UNIVERSIDADE DE SÃO PAULO \\ ESCOLA DE ENFERMAGEM DE RIBEIRÃO PRETO \\ DEPARTAMENTO DE ENFERMAGEM GERAL ESPECIALIZADA
}

\title{
ESTUDO DA OCORRÊNCIA DE ACIDENTES ENTRE TRABALHADORES DE UMA INDÚSTRIA FRIGORÍFICA DO ESTADO DE SÃO PAULO
}

\begin{abstract}
Dissertação apresentada à Escola de Enfermagem de Ribeirão Preto da Universidade de São Paulo para obtenção do título de Mestre em Enfermagem Fundamental.

Área de Concentração: Enfermagem

Linha de Pesquisa: Saúde do Trabalhador
\end{abstract}

Orientadora: Profa. Dra . Maria Helena Palucci Marziale 
AUTORIZO A REPRODUÇÃO E DIVULGAÇÃO TOTAL OU PARCIAL DESTE TRABALHO, POR QUALQUER MEIO CONVENCIONAL OU ELETRÔNICO, PARA FINS DE ESTUDO E PESQUISA, DESDE QUE CITADA A FONTE.

\section{FICHA CATALOGRÁFICA}

Campoamor, Marília Marcondes

Estudo da ocorrência de acidentes entre trabalhadores de uma indústria frigorífica do Estado de São Paulo. Ribeirão Preto, 2006. 96p.il:30cm

Dissertação (Mestrado - Programa de Pós Graduação em Enfermagem Fundamental). Escola de Enfermagem de Ribeirão Preto - Universidade de São Paulo.

Orientadora: Marziale, Maria Helena Palucci

1.Acidentes de trabalho 2.Saúde Ocupacional 3.Trabalho 4. Enfermagem 5.Risco Ocupacional 6. Indústria de processamento de alimentos. 


\section{FOLHA DE APROVAÇÃO}

Marília Marcondes Campoamor

Estudo da ocorrência de acidentes entre trabalhadores de uma indústria frigorífica do Estado de São Paulo

Dissertação apresentada à Escola de Enfermagem de Ribeirão Preto/ Universidade de São Paulo para obtenção do título de Mestre.

Área de Concentração: Enfermagem Fundamental.

Linha de Pesquisa: Saúde do Trabalhador.

Aprovado em: / / 2006

\section{Banca Examinadora}

Dra. Maria Helena Palucci Marziale

Prof. Associado da Escola de Enfermagem de Ribeirão Preto/USP

Dra. Vera Lúcia Navarro

Prof. Doutor da Faculdade de Filosofia Ciências e Letras de

Ribeirão Preto/USP 


\section{AGRADECIMENTOS}

Aos meus pais, José Luiz Gonzalez Campoamor (in memória) e Rita de Cássia Vieira Marcondes Campoamor, a gratidão pela minha existência, e pela minha formação. Abraços

Á Profa. Maria Helena Palucci Marziale, pela dedicação, compreensão e na confiança por sempre acreditar no meu potencial. Em um momento tão decisivo de minha vida, teve a coragem de assumir trabalho comigo em um tempo limitado.

Á Profa. Maria Lúcia do Carmo Cruz Robazzi, por todos os anos em que estivemos trabalhando juntas, desde á graduação, especialização e mestrado. Sempre foi meu ombro amigo, em todas as dificuldades surgidas ao longo desses nove anos de convivência. Obrigada por acreditar em mim.

Ao Prof. Vanderley José Haas, pelo aprendizado a respeito da perseverança, paciência e pelo apoio inexorável na finalização e concretização do meu trabalho.

Á Profa. Vera Lúcia Navarro, pela grande contribuição social na saúde do trabalhador, que foram adicionadas á minha experiência acadêmica. 


\section{AGRADECIMENTOS ESPECIAIS}

Ao meu querido chefe Robson César Triches, por todos os ensinamentos no âmbito profissionale pessoal, talvez sem eles não tivesse amadurecido o suficiente para concretizar esse projeto. Agradeço também pelo apoio, nas minhas liberações da empresa nas inúmeras vezes que necessitei para a finalização do mestrado.

Á minha querida amiga e irmã Ana Claudia Cayres, provavelmente sem o seu apoio e preocupação já tivesse desistido de uma etapa tão difícil e importante da minha vida.

Aos meus queridos amigos, Paulo Celso Prado Telles Filho e Elaine Maria Leite Rangel, pelo apoio, dedicação e confiança no meu trabalho.

Á todos os meus familiares, em especial, aos meus queridos avós, Pepe e Luiza, ao meu amado pai (in memóriam), José Luiz Gonzales Campoamor, ao meu querido tio, Pedro Gonzalez Campoamor, meu eterno agradecimento por hoje, ontem e pelo amanhã.

Á equipe de segurança do trabalho da Coperfrango, pela colaboração, atenção e interesse pelo meu trabalho.

Ao senhor Diretor Presidente da Coperfrango, Carlos Roberto Garcia, pela intensa colaboração e confiança neste trabalho.

Á senfora Solange Maria Risse Costa, pelo carinho e colaboração.

Á diretora do Campus VIII, da Vniversidade Camilo Castelo Branco, Maria Arlete Colussi, e á Coordenadora do Curso de Enfermagem, Ana Flora Fogaça Go66o, pelo apoio e confiança. 
A vida está cheia de desafios que, se aproveitados de forma criativa transformam-se em oportunidades." (Maxwell Maltz) 


\section{RESUMO}

CAMPOAMOR, M. M. Estudo da ocorrência de acidentes entre trabalhadores de uma indústria frigorífica do Estado de São Paulo. 86.p. Dissertação (Mestrado) - Escola de Enfermagem de Ribeirão Preto, Universidade de São Paulo, São Paulo, 2006.

O trabalho em frigorífico compreende atividades repetitivas, ritmo intenso de trabalho, realizado em ambientes com inadequados níveis de iluminação, ruído e temperatura, com presença de poeira, pequenos espaços e freqüente manipulação de instrumentos cortantes. Tais características tornam o trabalho exaustivo e, perigoso e assim torna-se, interessante objeto de investigação, com relevância social devido ao grande número de indústria do setor agropecuário no País. Trata-se de estudo não experimental, descritivo quantitativo, epidemiológico, baseado em dados secundários com objetivo de analisar a ocorrência de Acidente de Trabalho (AT) em uma indústria frigorífica. Foi realizado em uma indústria de abate e processamento de carnes, situada no interior do Estado de São Paulo. A população alvo foi constituída pelos ATs que tiveram ocorrências de Comunicações de Acidentes de Trabalho (CAT), registradas no Serviço Especializado de Segurança e Medicina do Trabalho (SEESMET), nos anos 2004 e 2005. Os dados foram coletados por meio de análise documental das CATs, sendo identificadas as características sóciodemográficas dos trabalhadores acidentados, a caracterização dos acidentes de trabalho e calculado o custo dos dias de trabalho perdidos devido á ocorrência do acidente. Os resultados foram 137 AT, dos quais 134 AT $(97,8 \%)$ foram acidentes típicos e $3(2,2 \%)$ acidentes de trajeto. Os AT foram sofridos por 135 trabalhadores que executam suas atividades laborais em diferentes unidades da empresa, com as seguintes características: idade entre 18 e 73 anos, com maior prevalência entre 25 e 40 anos de idade, com freqüência de 56 (41,5\%); trabalhadores do sexo masculino $108(80 \%)$, casados $59(43,7 \%)$ e apresentando média de salário mensal de $\mathrm{R} \$ 572,74$. A maioria dos trabalhadores acidentados exercia ocupações de ajudante de abatedouro (62,2 \%) e ajudante de serviços gerais $(9,6 \%)$ e a unidade de aves foi o local de trabalho onde os AT mais ocorreram, ou seja, $65,7 \%$ indivíduos se acidentaram no referido local. Do total de AT, 102 (74,5\%) ocasionaram afastamento dos trabalhadores. No turno matutino, foi registrada a maior freqüência dos $A T, 47,4 \%$. Quanto ao agente causador, os instrumentos de trabalho representaram $42,3 \%$ das ocorrências, seguidos pelo ambiente $(39,4 \%)$. Dentre os AT, $118(86,1 \%)$ foram responsáveis por afastamento do trabalhador de suas atividades laborais em período de até 15 dias e em 2 (1,5\%) em período superior a 16 dias. Em 17 (12,4\%) dos registros não continha informações a esse respeito. As causas diagnósticas mais freqüentes atribuídas ao AT, foram traumatismo superficial de cabeça e outros traumatismos específicos do tornozelo e do pé $(16,02 \%)$, doenças do sistema osteomuscular e tecido conjuntivo $(10,9 \%)$; causas externas, exposição á força mecânica, acidentes com riscos respiratórios, exposição a corrente elétrica, temperaturas extremas (8,03\%), traumatismos superficiais, envolvendo múltiplas regiões do corpo (2,19\%). Em relação aos custos ocasionados pelos AT devido á perda dos dias de trabalho, foi identificado o montante de $\mathrm{R} \$ 20,427,67$ no biênio estimado.

Palavras Chave: acidente de trabalho, saúde ocupacional,indústria de alimentos, enfermagem. 


\begin{abstract}
CAMPOAMOR, M. M. A study on the occurrence of accidents among workers at a meat packing industry in the State of São Paulo. 86pp. Thesis (Master's) University of São Paulo at Ribeirão Preto College of Nursing, São Paulo, 2006.
\end{abstract}

Meat packing work is marked by repetitive activities; intense work rhythm; environments with inadequate levels of illumination, noise and temperature; presence of dust; small spaces and frequent handling of cutting instruments. These characteristics make this activity exhausting and dangerous and, hence, an interesting object of study, but is socially relevant due to the large quantity of agriculture and cattle industries in the country. We carried out a non-experimental, descriptive, quantitative and epidemiological study, based on secondary data, aimed at analyzing the occurrence of Work Accidents (WA) at a meat packing industry. The research was carried out at a meat processing and packing industry located in the interior of the State of São Paulo. The target population included Work Accident Notifications (CAT) registered at the Specialized Occupational Safety and Medicine Service (SEESMET) in 2004 and 2005. Data were collected through document analysis of the CAT, identifying the sociodemographic characteristics of the accident victims, characterizing work accidents and calculating the cost of the work days lost due to the accident occurrence. We found 137 WA, $134(97.8 \%)$ of which were typical and $3(2.2 \%)$ commuting accidents. Victims were 135 workers active in different company units, with the following characteristics: workers were between 18 and 73 years old, with 56 (41.5\%) professionals between 25 and 40 years old; 108 workers were men (80\%); 59 (43.7\%) were married; average monthly salaries amounted to $\mathrm{R} \$ 572.74$ reais. Most accident victims were either meat packing aids $(62.2 \%)$ or general service aids (9.6\%) and a majority of accidents, that is, $65.7 \%$, happened at the poultry unit. One hundred two $(74.5 \%)$ of the total number of accidents caused sick leave. The greatest WA frequency (47.4\%) was found during the morning shift. As to the causal agent, work instruments represented $42.3 \%$ of the events, followed by the environment (39.4\%). One hundred eighteen of the WA (86.1\%) were responsible for a sick leave of up to 15 days and, in 2 cases (1.5\%), for more than 16 days. Seventeen (12.4\%) accident registers did not contain any information in this respect. The most frequent diagnoses were superficial head injuries and other specific ankle and foot injuries (16.02\%), diseases of the musculoskeletal system and connective tissue (10.9\%); external causes, exposure to mechanical forces, accidents with respiratory risks, exposure to electrical current, extreme temperatures (8.03\%), superficial injuries involving multiple body regions (2.19\%). As to the costs incurred due to the loss of work days caused by the WA, we identified that the company lost an estimated amount of $\mathrm{R} \$ 20,427.67$ Reais during the study period.

Key words: work accident; health occupational; meat packing industry; nursing. 


\section{RESUMEN}

CAMPOAMOR, M. M. Estudio de la ocurrencia de accidentes entre trabajadores de una industria frigorífica del Estado de São Paulo. .86.hh. Disertación (Maestría) Escuela de Enfermería de Ribeirão Preto, Universidad de São Paulo, São Paulo, 2006.

El trabajo en frigorífico abarca actividades repetitivas; intenso ritmo de trabajo; ambientes con inadecuados niveles de iluminación, ruido y temperatura; presencia de polvos; pequeños espacios y frecuente manipulación de instrumentos cortantes. Tales características hacen el trabajo exhaustivo y peligroso y, así, un objeto de investigación interesante, pero de relevancia social debido a la gran cantidad de industrias del sector agropecuario en el país. Se trata de un estudio no experimental, descriptivo, cuantitativo y epidemiológico, basado en datos secundarios, con objeto de analizar la ocurrencia de Accidentes de Trabajo (AT) en una industria frigorífica. Fue llevado a cabo en una industria cárnica, ubicada en el interior del Estado de São Paulo. La población blanco eran las Comunicaciones de Accidentes de Trabajo (CAT) registradas en el Servicio Especializado de Seguridad y Medicina del Trabajo (SEESMET) en 2004 y 2005. Los datos fueron recolectados mediante análisis documental de las CAT, identificando las características sociodemográficas de los trabajadores accidentados, caracterizando los accidentes de trabajo y calculando el costo de los días de trabajo perdidos debido a la ocurrencia del accidente. Resultaron 137 AT, de los cuales 134 (97,8\%) fueron accidentes típicos y 3 (2,2\%) accidentes de trayecto. Las víctimas fueron 135 trabajadores que ejecutaban sus actividades laborales en diferentes unidades de la empresa con las siguientes características: edad entre 18 y 73 años, con mayor prevalencia entre 25 y 40 años de edad con una frecuencia de 56 (41,5\%); trabajadores del sexo masculino 108 $(80 \%)$, casados $59(43,7 \%)$ y presentando un salario mensual promedio de $\mathrm{R} \$$ 572,74 reales. La mayoría de los trabajadores accidentados ejercía las ocupaciones de ayudante de matadero $(62,2 \%)$ y ayudante de servicios generales $(9,6 \%)$ y la unidad de aves fue el sitio de trabajo donde los AT ocurrieron con mayor frecuencia, o sea, el $65,7 \%$ de los individuos se accidentó en ese sitio. Del total de AT, 102 $(74,5 \%)$ llevaron a la ausencia de las víctimas. Se registró la mayor frecuencia $(47,4 \%)$ de los AT durante el turno matutino. En cuanto al agente causador, los instrumentos de trabajo representaron el $42,3 \%$ de las ocurrencias, seguidos por el ambiente (39,4\%). Entre los AT, $118(86,1 \%)$ fueron responsables por la ausencia del trabajador de sus actividades laborales durante un período de hasta 15 días y, en 2 casos $(1,5 \%)$, durante más de 16 días. Diecisiete $(12,4 \%)$ de los registros no contenían informaciones a ese respecto. Las causas diagnósticas más frecuentes atribuidas al AT fueron traumatismo superficial de cabeza y otros traumatismos específicos del tobillo y pié (16.02\%), enfermedades del sistema osteomuscular y tejido conjuntivo (10.9\%); causas externas, exposición a fuerza mecánica, accidentes con riesgos respiratorios, exposición a corriente eléctrica, temperaturas extremas $(8,03 \%)$, traumatismos superficiales que afectan múltiples regiones del cuerpo (2,19\%). Con relación a los costos ocasionados por los AT debido a la pérdida de los días de trabajo, se identificó el importe estimado de $\mathrm{R} \$ 20.427,67$ Reales durante el bienio.

Palabras-clave: accidentes de trabajo; salud ocupacional; industria frigorífica; enfermería. 


\section{LISTA DE FIGURAS}

Figura 1 - Evolução mensal dos coeficientes de freqüência de acidentes, para a empresa, entre janeiro 2004 á

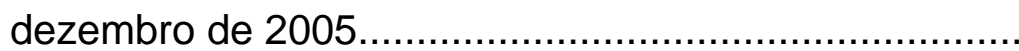

Figura 2 - Evolução temporal dos coeficientes, de freqüência de acidentes, por unidade, de janeiro de 2004 a dezembro de 2005

Figura 3 - Evolução temporal dos coeficientes de freqüência de acidentes por unidades, de janeiro de 2004 a dezembro de 2005 


\section{LISTA DE TABELAS}

Tabela 1 - Distribuição dos Acidentes de Trabalho segundo o tipo de acidente, afastamento e turno de trabalho. Descalvado-

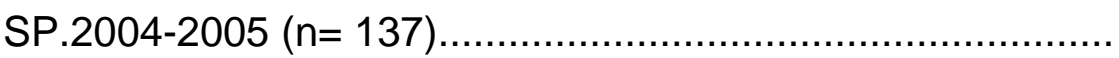

Tabela 2 - Distribuição dos trabalhadores acidentados, segundo faixa etária, estado civil, sexo e salário. Descalvado-SP, 2004$2005(n=135)$

Tabela 3 - Distribuição dos trabalhadores acidentados, segundo a ocupação e/ou profissão. Descalvado-SP, 2004-2005 $(n=135)$

Tabela 4 - Distribuição dos trabalhadores acidentados, segundo setor de atividades Descalvado-SP, 2004-2005 $(n=135)$.

Tabela 5 - Distribuição dos acidentes de trabalho, segundo o diagnóstico, dias de afastamento e agente causador, descrito na CAT de trabalhadores. Descalvado-SP, 2004$2005(n=137)$

Tabela 6 - Coeficientes de freqüência de acidentes na empresa nos anos 2004 e 2005

Tabela 7 - Coeficientes de freqüência de acidentes (CF) para as unidades componentes da empresa, nos anos 2004 e 2005 


\section{SUMÁRIO}

\section{RESUMO \\ ABSTRACT \\ RESUMEM \\ LISTA DE FIGURAS \\ LISTA DE TABELAS}

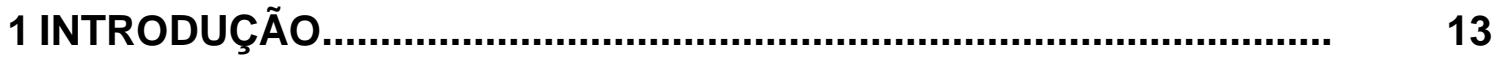

1.10 processo trabalho saúde-doença........................................... 15

1.2 Acidentes de trabalho e doenças ocupacionais que acometem os trabalhadores de abate e processamento de alimentos.......... 24

2. OBJETIVOS................................................................................... $\quad 31$

2.1 Objetivo Geral........................................................ 32

2,2 Objetivo Específico...................................................... 32

3. MATERIAL E MÉTODO 33

3.1 Delineamento da pesquisa ................................................ 34

3.2 Local........................................................................... 34

3.2 População..................................................................... 34

3.3 Definição de variáveis......................................................... 35

3.4 Procedimentos................................................................. 35

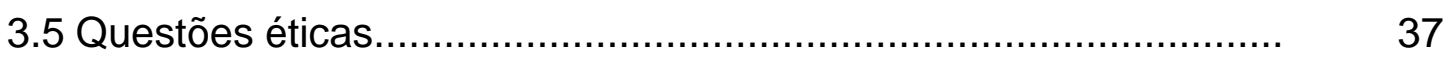

4. RESULTADOS E DISCUSSÃO........................................................ $\quad 38$

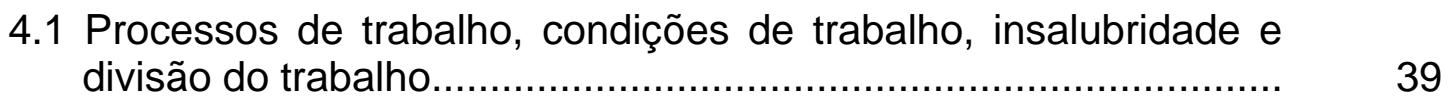

4.2 Acidentes de Trabalho................................................. 54

5. CONSIDERAÇÕES FINAIS.................................................... 78

6. REFERÊNCIAS BIBLIOGRÁFICAS............................................. 83

ANEXOS 
Enquanto aluna de graduação, realizei estágios voluntários nos ambulatórios de empresas da região de Ribeirão Preto - SP, iniciando assim minha aproximação com a área de Saúde do Trabalhador e Enfermagem do Trabalho. Ainda, durante a graduação, desenvolvi estudo sobre a problemática da subnotificação dos Acidentes de Trabalho e, por meio dessa experiência, iniciei minha formação no campo da pesquisa em Saúde do Trabalhador. Após a graduação, realizei o curso de Especialização em Enfermagem do Trabalho, atuei como enfermeira do trabalho em uma usina de cana - de- açúcar e em indústria de processamento e industrialização de carne de aves e suínos. Atuei também na formação de recursos humanos, ministrando aulas em cursos para Técnicos de Segurança do Trabalho e Auxiliar de Enfermagem do Trabalho e em cursos de Graduação de Enfermagem e Educação Física.

Durante a atuação na indústria frigorífica, identifiquei que os trabalhadores estavam expostos a uma série de fatores de riscos ocupacionais os quais podem acarretar-Ihes adoecimento pelo trabalho e que, na literatura nacional, pouca atenção tem sido direcionada á referida população de trabalhadores. Diante dessa constatação, fui motivada a realizar a pesquisa ora apresentada por considerar que os resultados das pesquisas são necessários para o aprimoramento da prática profissional.

Assim, considerando minhas funções enquanto enfermeira do trabalho, senti a necessidade de investigar a ocorrência de acidentes de trabalho entre os trabalhadores de uma indústria frigorífica com a finalidade de elaborar medidas preventivas para serem adotadas em nossa atuação profissional como membro do SESMET. 
Com a finalidade de buscar sustentação teórica para a realização desta pesquisa, realizei revisão da literatura, buscando contextualizar os aspectos relevantes no processo trabalho - saúde - doença e as evidências científicas sobre os acidentes de trabalho e doenças ocupacionais que acometem os trabalhadores na indústria de abate e processamento de alimentos.

\subsection{0 processo trabalho - saúde - doença}

O trabalho é considerado por muitos estudiosos como forma elevada de socialização humana, representando muitas vezes aprendizado e um contato permanentes entre as pessoas. No início, o trabalho teve a finalidade de atender uma necessidade existencial, servindo para elevar a sua condição de animal para homem. Com a evolução das organizações, os processos de trabalho diferenciamse, e aquele homem que dominava todo o processo de trabalho, do início ao fim, já não é mais capaz de, sozinho, produzir tudo aquilo de que necessita. Assim, o processo de trabalho sofre uma divisão, em que um homem passa a realizar etapas, não conseguindo muitas vezes visualizar o seu produto final. Portanto, o modo como se produz a existência humana foi se modificando ao longo da história, passando pelo modo de produção comunal, tribal e feudal até se chegar ao modo de produção capitalista até hoje vigente (MUROFUSE, 2000, p. 9).

A prática social vivida pelo homem, utilizada para garantir a sua sobrevivência, muitas vezes coloca-o numa situação conflituosa, pois, se por um lado, ela pode garantir a sua vida, por outro, contraditoriamente, também pode causar doenças, diminuindo a sua capacidade vital e, até mesmo, provocando a sua morte. Assim, o mesmo trabalho que proporciona as condições para a sua 
humanização, torna-se, nesse processo, fator de sofrimento físico, psíquico, mental e/ou social quando não executado em condições adequadas (ORSO, et al., 1998).

Assim, a manutenção da saúde é essencial para a execução das atividades de trabalho e saúde e deve ser compreendida como:

\footnotetext{
"elevado grau de bem-estar físico, mental e social dos trabalhadores em todas as suas atividades, impedir qualquer dano causado pelas condições de trabalho e proteger contra riscos resultantes de agentes prejudiciais á saúde..." (CACCIAMALI et, al, 2003. p.3).

"para todas as pessoas, a saúde mental, física e social são fios de vida estreitamente entrelaçados e profundamente interdependentes..." (CACCIAMALI et, al, 2003. p.4).
}

A doença, por sua vez, deve ser compreendida como um atributo da vida, constituindo-se em processo biológico tão antigo quanto a vida. O processo saúdedoença consiste na expressão da instabilidade a que um organismo vivo está exposto no mundo em constante mudança. A doença está associada às dimensões biológicas, psicológicas, sociais, culturais e econômicas (MUROFUSE, 2000, p.13), no entanto, o adoecimento provocado pelo trabalho não deve ser entendido como algo natural ou normal.

A saúde do trabalhador compreende alguns condicionantes sociais, econômicos, tecnológicos e organizacionais responsáveis pelas condições de vida, e os fatores de risco ocupacional, físicos, químicos, biológicos, mecânicos e aqueles decorrentes da organização laboral, presentes nos processos de trabalho. Assim, as ações de saúde do trabalhador têm como foco as mudanças nos processos de trabalho que contemplem as relações saúde-trabalho em toda a sua complexidade, por meio de atuação multiprofissional, interdisciplinar e intersetorial (BRASIL MS, 2001).

Os trabalhadores são considerados sujeitos e partícipes das ações de saúde, quer seja no individual ou no coletivo das organizações, incluindo assim 
estudos das condições de trabalho, identificação de mecanismos de intervenção técnica para melhoria e adequação e o controle dos serviços de saúde prestados (BRASIL MS , 2001).

Os perfis de adoecimento e morte da população em geral também são compartilhados pelos trabalhadores, em função de sua idade, gênero, grupo social ou inserção em um grupo específico de risco. Além disso, os trabalhadores podem adoecer ou morrer por causas relacionadas ao trabalho, como conseqüência da profissão que exercem ou exerceram, ou das condições adversas em que seu trabalho é ou foi realizado. Para Schilling (1984) apud Brasil. MTE (2001, p. 14), as doenças relacionadas ao trabalho podem ser divididas em três grupos, quando adotando como critério a natureza dessa relação, qual seja:

- grupo I: doenças tipificadas pelas intoxicações agudas de origem ocupacional.

- grupo II: doenças em que o trabalho pode ser um fator de risco, contributivo, mas não necessário, exemplificado pelas doenças comuns, mais freqüentes ou mais precoces em determinados grupos ocupacionais e para os quais o nexo causal é de natureza eminentemente epidemiológica. A hipertensão arterial e as neoplasias malignas (cânceres), em determinados grupos ocupacionais ou profissionais, constituem exemplo típico.

- grupo III: doenças em que o trabalho é provocador de um distúrbio latente, ou agravador de doença já estabelecida ou preexistente, ou seja, com causa, tipificadas pelas doenças alérgicas de pele e respiratórias e pelos distúrbios mentais, em determinados grupos ocupacionais ou profissões.

Para Mendes e Dias (1999) apud Brasil. MTE (2001, p. 27), o perfil de adoecimento e morte dos trabalhadores pode ser resumido em quatro grupos de 
causas:

- doenças comuns, aparentemente sem qualquer relação com o trabalho;

- doenças comuns (crônico-degenerativas, infecciosas, neoplasias, traumáticas, etc.) eventualmente modificadas no aumento da freqüência de sua ocorrência ou na precocidade de seu surgimento em trabalhadores, sob determinadas condições de trabalho. A hipertensão arterial em motoristas de ônibus urbanos, nas grandes cidades, exemplifica essa possibilidade;

- a asma brônquica, a dermatite de contato, alérgica, a perda auditiva induzida pelo ruído (ocupacional), doenças músculo-esqueléticas e alguns transtornos mentais exemplificam essa possibilidade, na qual, em decorrência do trabalho, soma-se (efeito aditivo) ou multiplicam-se (efeito sinérgico) as condições provocadoras ou desencadeadoras desses quadros nosológicos;

- agravos á saúde específicos, tipificados pelos acidentes do trabalho e pelas doenças profissionais. A silicose e asbestose exemplificam esse grupo de agravos específicos.

As causas de adoecimento pelo trabalho podem estar relacionadas a fatores biológicos, físicos, químicos, antiergonômicos, psicológicos e sociais e as formas como esse adoecimento ocorre vêm sendo estudadas há séculos, sendo que o marco de maior evidência da relação trabalho-doença ocorreu no ano de 1700, quando Ramazzini descreveu as doenças relacionadas a mais de 60 profissões, arrolando as atividades, as doenças conseqüentes e as medidas de prevenção e tratamento para cada uma delas, (MENDES, 1995).

As formas de adoecimento pelo trabalho vêm sendo modificadas ao longo da história, devido às transformações nos processos de produção e de organização 
do trabalho, decorrentes da incorporação de tecnologias e estratégias gerenciais. Antunes Lima et al. (1999) descrevem um conjunto de doenças que podem estar relacionadas com a implementação de novos métodos de trabalho em ambientes altamente competitivos e inseguros com relação à manutenção dos postos de trabalho, dentre as quais ressalta-se a Síndrome da Fadiga Crônica, Karoshi, uso abusivo de álcool e drogas e depressão.

O adoecimento pelo trabalho é tratado em termos de legislação em nosso país como Doença do Trabalho e Doença Profissional. A Doença do Trabalho é aquela adquirida ou desencadeada em função de condições especiais, em que o trabalho é realizado e com ele se relaciona diretamente. Doença Profissional é aquela produzida ou desencadeada pelo exercício do trabalho peculiar a determinada atividade. É decorrente das condições especiais ou excepcionais em que o trabalho é executado, e, desde que diretamente relacionado com a atividade exercida, cause redução da capacidade para o trabalho, (BRASIL. MT, Decreto-Lei $n^{\circ}$ 357, 1991 apud MENDES, 1995).). As duas formas de adoecimento são consideradas Acidentes de Trabalho na legislação.

Acidente de trabalho é definido como "aquele que ocorre pelo exercício do trabalho a serviço da empresa ou pelo exercício do trabalho dos segurados especiais, provocando lesão corporal ou perturbação funcional que cause a morte ou a perda ou redução, permanente ou temporária, da capacidade para o trabalho", e são classificados em acidentes de trabalho típicos e de trajeto, (BRASIL, MT, Decreto-Lei no. 357, 1991).

Equipara-se também ao acidente do trabalho, segundo a Lei n 8213/91 (Brasil,1999. Lei no. 8.213, de 24 de julho de 1991):

I - o acidente ligado ao trabalho que, embora não tenha sido a causa única, haja 
contribuído diretamente para a morte do segurado, para redução ou perda da sua capacidade para o trabalho, ou produzido lesão que exija atenção médica para a sua recuperação;

II - o acidente sofrido pelo segurado no local e no horário do trabalho, em conseqüência de:

a) ato de agressão, sabotagem ou terrorismo praticado por terceiro ou companheiro de trabalho;

b) ofensa física intencional, inclusive de terceiro, por motivo de disputa relacionada ao trabalho;

c) ato de imprudência, de negligência ou de imperícia de terceiro ou de companheiro de trabalho;

d) ato de pessoa privada do uso da razão;

e) desabamento, inundação, incêndio e outros casos fortuitos ou decorrentes de força maior;

III - a doença proveniente de contaminação acidental do empregado no exercício de sua atividade;

IV - o acidente sofrido pelo segurado ainda que fora do local e horário de trabalho:

a) na execução de ordem ou na realização de serviço sob a autoridade da empresa;

b) na prestação espontânea de qualquer serviço à empresa para lhe evitar prejuízo ou proporcionar proveito;

c) em viagem a serviço da empresa, inclusive para estudo quando financiada por essa dentro de seus planos para melhor capacitação da mão-de-obra, independentemente do meio de locomoção utilizado, inclusive veículo de propriedade do segurado; 
d) no percurso da residência para o local de trabalho ou desse para aquela, qualquer que seja o meio de locomoção, inclusive veículo de propriedade do segurado.

Os riscos de ocorrência de acidentes típicos e doenças ocupacionais variam para cada ramo de atividade econômica, em função de tecnologias utilizadas, condições de trabalho, características da mão-de-obra empregada e medidas de segurança adotadas, dentre outros fatores. A natureza do risco profissional, conforme definem BEDRIKOW, BAUMECKER e BUSCHINELLI (1996, p.1):

\begin{abstract}
“... compreende agentes mecânicos que em geral produzem efeitos de forma súbita e lesões do tipo traumáticas - acidentes do trabalho - e agentes físicos, químicos e biológicos, causadores de doenças profissionais. Acrescentam-se os riscos ergonômicos e, com importância crescente, fatores psicossociais com repercussão em especial sobre a saúde mental dos trabalhadores. Mudanças nas tecnologias e nas formas de organização do trabalho, informatização, descaracterização da empresa como único local de trabalho e trabalho em domicílio, criam novas formas de risco..."
\end{abstract}

Os acidentes de trabalho representam um sistema complexo de problemas, envolvendo vários fatores, desde aqueles de ordem geral até aqueles em níveis individuais, com pesos variáveis e funcionando em combinações cambiantes. Constituem-se no principal evento mórbido entre trabalhadores brasileiros no exercício do seu ofício, tendo como conseqüências repercussões na qualidade de vida de famílias que estão inseridas nesse contexto da economia brasileira. Nas últimas duas décadas, ocorreram mais de 29 milhões de acidentes e mais de cem mil mortes relacionadas ao trabalho registradas no Brasil, sendo que essas mortes atingem a população jovem (WUNSCH FILHO, 1999).

No Brasil, a População Economicamente Ativa (PEA), segundo estimativa do Instituto Brasileiro de Geografia e Estatística - IBGE (PNAD 2002), era de 82902 480 pessoas, das quais 75471556 consideradas ocupadas. Dessa população, , 41 755449 eram empregados; 5833448 eram empregados domésticos; 17224328 
eram trabalhadores por conta própria; 3317084 eram empregadores; 3006860 eram trabalhadores na produção para próprio consumo e construção para próprio uso; e 4334387 eram trabalhadores não remunerados. Portanto, entre os 75471 556 trabalhadores ocupados em 2002, apenas 22.903.311 (com carteira assinada) possuíam cobertura da legislação trabalhista e do Seguro de Acidentes do Trabalho. A distribuição dos trabalhadores, segundo setor produtivo, revela que, das 75.471.556 pessoas consideradas ocupadas (PNAD-2002), 19,53\% estão no setor Agrícola e Extrativista; $13,72 \%$ no setor da Indústria de Transformação e 17,15\% no setor de Comércio e Reparação. Essa diversidade e complexidade das condições e ambientes de trabalho dificultam o estabelecimento de prioridades $\mathrm{e} o$ desenvolvimento de alternativas de eliminação e controle dos riscos (BRASIL MPS, 2004, p. 2).

Esses números podem não representar a realidade, uma vez que muitos acidentes de trabalho não são notificados e não constam das estatísticas.

No período de 1999 a 2003, a Previdência Social registrou 1875190 acidentes de trabalho, sendo 15293 com óbitos e 72020 com incapacidade permanente, média de 3059 óbitos/ano, entre trabalhadores formais. O coeficiente médio de mortalidades, no período considerado, foi de 14,84 por 100000 trabalhadores. A comparação desse coeficiente com o de outros países, tais com a Finlândia, 2,1 (2001), França, de 4,4 (2000), Canadá, 7,2 (2002) e Espanha 8,3 (2003) demonstram que o risco de morrer por acidente de trabalho no Brasil é cerca de duas a cinco vezes maior. No mesmo período, o Instituto Nacional do Seguro Social-INSS concedeu 854147 benefícios por incapacidade temporária ou permanente, devido a acidentes do trabalho, ou seja, a média de 3235 auxílios doença e aposentadorias por invalidez por dia útil. No mesmo período, foram 
registrados 105514 casos de doenças relacionadas ao trabalho. A totalização dos gastos da Previdência Social com pagamentos de benefícios acidentários e aposentadoria especial (concedida em face de exposição a agentes prejudiciais á saúde ou integridade física, com redução no tempo de contribuição) foi de 8,2 bilhões de reais. * O número de dias de trabalho perdidos em razão dos acidentes aumenta o custo da mão de obra no Brasil, encarecendo a produção e reduzindo a competitividade do país no mercado externo. Estima-se que o tempo de trabalho perdido anualmente, devido aos acidentes de trabalho, seja de 106 milhões de dias, apenas no mercado formal, considerando-se os períodos de afastamento de cada trabalhador (BRASIL MPS, 2004, p.3).

Segundo Pastore (1998) apud Brasil. MS. (2001), para cada real gasto com o pagamento de benefícios previdenciários, a sociedade paga quatro reais, incluindo gastos com saúde, horas de trabalho perdidas, reabilitação profissional, custos administrativos etc. Esse cálculo eleva o custo total, para o país, de aproximadamente 33 bilhões de reais por ano.

Assim, constata-se que a AT oferece prejuízos às instituições empregadoras, governamentais e ao próprio trabalhador e suas famílias que, muitas vezes, ficam incapacitados permanentemente para o exercício do trabalho, quando não morrem por ele.

A literatura evidencia que usualmente o AT remete á noção de "fatalidade", "obra do azar", erro grosseiro" e eventos que ocorrem pelo acaso ou por causas religiosas e desconhecidas "ou devido à" culpa "do próprio trabalhador" (BORSOI, 2005 p 1).

\footnotetext{
* O custo da mão-de-obra no Brasil é baixíssimo e é este baixo custo que a torna competitiva no mercado internacional. "Levantamento do Departamento de Estatísticas do Trabalho nos EUA, mostrar que o custo do trabalho na indústria brasileira é da ordem de US\$ 3 dólares por hora, segundo dados de 2004. Na coréia por exemplo é de US\$11,52 dólares ". Folha de São Paulo, 1/05/2005. Caderno B.6
} 
Os acidentes de trabalho devem pertencer a um sistema de promoção e prevenção á saúde e segurança do trabalhador que possuam metas voltadas para o acompanhamento do quadro de evolução geral das atividades econômicas (mais orientadas para os serviços), das formas de emprego (mais diversificadas, incluindo o trabalhado sem registro), da população ativa (como a inserção do trabalho feminino cada vez maior) e da sociedade em geral (mais diversificada, mas também marcada pela exclusão social). Dentro desse sistema, alguns dos tópicos mais importantes para aproximação dos profissionais da saúde ocupacional com a realidade do trabalho são as premissas, as qualidades do emprego, que incluem uma série de componentes solidários tais como tipos de qualificações requeridas, nível de formação dos trabalhadores, natureza da sua relação laboral, organização do seu trabalho e do seu horário de trabalho (OCCUPATIONAL SAFETY AND HEALTH OSHA, 2000).

No entanto, o AT pode ocorrer devido a inúmeros fatores que merecem ser estudados em cada situação de trabalho, considerando as características das atividades laborais, dos trabalhadores e do ambiente de trabalho.

\subsection{Acidentes de trabalho e doenças ocupacionais que acometem os} trabalhadores na indústria de abate e processamento de alimentos

Segundo Campbell (1999), as condições de trabalho nos processos de abate e industrialização de carnes teve suas primeiras descrições no ano de 1906 , tendo como marco o romance "The Junge", escrito por Upton Sinclair. O referido escritor aborda os riscos e os agravos à saúde aos quais os trabalhadores de 
frigoríficos estavam expostos, dentre os quais destacou os agentes: químicos (utilizados para realizar a higienização do chão de fábrica), mecânicos (devido ao manuseio excessivo com facas para os cortes da carne) e biológicos (devido à exposição a vários agentes infecto-pasitários, durante o processo de abate e evisceração dos animais). A partir de então, muitos esforços têm sido despendidos no intuito de diminuir as doenças e acidentes de trabalho nesse ramo de atividade, assim como a estruturação de legislações que amparam essa classe de trabalhadores.

A característica do trabalho em frigorífico compreende atividades repetitivas devido ao intenso processo de produção. Trabalhadores executam suas atividades laborais em ambientes inapropriados, onde as dificuldades incluem desde a iluminação, ruído, poeiras, espaço físico (nas quais os trabalhadores dividem seu pequeno espaço físico com outras centenas de trabalhadores que executam suas atividades, manipulando facas para o corte da carne). Isso torna o trabalho exaustivo e perigoso, principalmente devido à jornada de mais de oito horas de exposições a sangue, vísceras, carcaças e á inalação de odores fétidos, (HUMAN RIGHTS WATCH, 2004).

Como toda indústria, os frigoríficos também se adaptaram à evolução e modernização dos processos industriais, investindo em maquinários de alta complexidade tecnológica. Com isso, a produção/dia duplicou, as atividades, como conseqüência, ficaram mais intensas, o trabalho, sob pressão, tornou-se algo comum nesses ambientes de trabalho e o número de doenças e acidentes vêm aumentando gradativamente.

Schlosser (2001) descreve, em seu artigo, que, nos Estados Unidos, o número de indústrias que atuam no processo de abate e processamento de carnes 
tem mercado próspero, e sua expansão econômica destaca-se no mundo do trabalho. No Brasil, o setor representou no ano de 2003 US\$ 4,1 bilhões da economia nacional, assumindo a liderança do ranking dos maiores exportadores do setor avícola, sendo que a maior parte dos embarques estão direcionados para a Arábia Saudita, Japão, Alemanha, Países Baixos, Rússia e Hong Kong. A indústria frigorífica e responsável por $37 \%$ dos empregos no Brasil, por $42 \%$ do total de exportações e por 33\% do (PIB) Produto Interno Bruto (BRASIL MA,1998).

Nos Estados Unidos, segundo Schlosser (2001), muitos empregadores do setor de frigoríficos contratam mão de obra desqualificada, na maioria das vezes *imigrantes que se sujeitam a ganhar baixos salários e a trabalhar em condições precárias pois precisam sobreviver, e esses trabalhadores, devido aos problemas com o idioma e pela permanência ilegal no país não reclamam seus direitos e aceitam as condições impostas pelas empresas. Assim, verifica-se, quer seja em países desenvolvidos ou em desenvolvimento, que os trabalhadores de frigoríficos enfrentam condições laborais que os expõem á vitimização por acidente de trabalho e doenças ocupacionais.

A classificação de risco para a indústria de abate e processamento de aves, segundo a Norma Regulamentadora NR-4(BRASIL MTE, 2000) é o grau de risco 3, disposto em seu quadro de redimensionamento do Serviço Especializado em Segurança e Medicina do Trabalho (SESMET), encontra-se a quantidade de profissionais para atuar no serviço, baseando-se na exposição e, conseqüentemente nos riscos a que esses trabalhadores estão expostos.

Segundo dados da International Labour Organization, os acidentes e doenças do trabalho na indústria de abate e processamento de aves acontecem em

\footnotetext{
* Os imigrantes contratados pelos frigoríficos americanos, são em sua grande maioria de origem hispânica.
} 
contexto mundial. A pesquisa realizada pela organização supracitada destaca as estatísticas dos casos de acidentes e doenças como também o custo com indenizações devido ás seqüelas e outros tipos de mutilações (TOMADA, 2000).

Dentre os países que enfrentam essa questão, destaca-se a Austrália que, nos anos 1992 e 1993, gastou mais de 3,5 milhões de dólares com indenizações por acidente e doenças do trabalho em indústrias de abate e processamento.

$\mathrm{Na}$ Hungria, além das indenizações, as indústrias enfrentam outro fator agravante que são os dias de trabalho perdidos como conseqüência dos afastamentos gerados, os quais refletem diretamente na sua produtividade, pois nem sempre as vagas podem ou têm condições de serem substituídas, por ocasião desses afastamentos decorrentes de acidentes de trabalho e/ou enfermidades relativas ao mesmo e, tentando evitar que a produtividade diminua, as empresas, sem muitas opções, sobrecarregam os demais trabalhadores dos setores no intuito de amenizar a vaga "ociosa" (TOMADA, 2000).

No ano 2003, segundo dados estatísticos do Ministério do Trabalho, o país apresentou 1800000 casos de acidentes de trabalho somente no setor da agropecuária, na qual está inserida a atividade de abate e processamento de carnes (BRASIL MT, 2003).

Dessa forma, cria-se um ciclo vicioso, pois aqueles trabalhadores que estão sob pressão para recuperar a produtividade da vaga, então perdida, fadigamse por total falta de condições físicas e mentais, e novamente são vítimas de acidente ou doença do trabalho.

Para Personick \& Taylor Shirley (1989), as principais causas de acidentes e doenças do trabalho nas indústrias de processamento de aves e carnes são os ambientes e condições inadequadas de trabalho. Os autores supracitados 
realizaram pesquisa comparativa entre indústrias de processamento de aves e carnes e manufaturas e identificaram, que em relação aos indicadores estudados, as indústrias de processamento de aves e carnes possuem maior número de casos de acidentes e doenças do trabalho.

Essa questão se explica devido a algumas características próprias do trabalho em frigorífico. O processo de abate, mesmo com as perspectivas e projeções de automação das grandes empresas, ainda se faz manualmente, utilizando-se para isso de facas e atividades repetitivas na qual se emprega força muscular de todo membro superior (braço, punho e dedos). Além disso, durante a atividade de abate o trabalhador permanece grande parte de sua jornada em posição ortostática. As características da atividade devido à repetição de movimentos e a postura corporal adotada são fatores predisponentes a doenças osteomusculares relacionadas ao trabalho-DORT e ás lesões por esforço repetitivoLER.

A incidência de LER nos setores de embalagem e linhas de montagem de várias indústrias e bancos tem sido responsável por cerca de 80 a 90\% dos casos de doenças profissionais, registrados na Previdência Social nos últimos anos (PORTO FREITAS,1997).

Campbell (1999) descreve, em seu estudo as características individuais dos acidentes e doenças ocupacionais nas indústrias de abate e processamento de carne. A síndrome do túnel do carpo é uma das doenças musculoesqueléticas mais incidente nessa população, como também lacerações, amputações e perfurações são destacadas devido à atividade e instrumento de trabalho pertinentes á natureza dos processos a serem realizados.

Segundo Scholosser (2001), os principais tipos de acidentes de trabalho 
que ocorrem nos frigoríficos são lacerações severas, amputações de membros, queimaduras, intoxicações por produtos de limpeza, ferimentos oculares e o aparecimento das doenças ocupacionais devido aos traumas osteomusculares. A maioria dos trabalhadores expostos a esse tipo de acidente fica com seqüelas, impossibilitados, assim, de retornar ao trabalho, tornado-se dependentes dos benefícios da Seguridade Social.

Segundo dados da Government Accountability Office-GAO, nos frigoríficos, os trabalhadores estão expostos a agentes químicos, variações de temperatura, incluindo extremos de máxima e mínima, com intervalos que podem chegar a 60 segundos de diferença entre uma atividade e outra, ruídos intermitentes produzidos pelas máquinas e os fatores estressores devido à pressão do trabalho que se baseia especificamente na produtividade (UNITED STATES GOVERNMENT ACCOUNTABILITY GAO, 2005).

No estudo realizado por Giampaoli (1981), foi constatado o aumento da freqüência de acidentes em baixas temperaturas. O referido autor atribui a ocorrência de tais acidentes à perda da destreza manual devido à vasoconstrição periférica e diminuição da atividade muscular.

Além dos fatores relacionados ao ambiente, o contato com animais pode causar danos á saúde dos trabalhadores de frigoríficos dentre elas estão as infecções causadas pela Salmonella, Brucella, Mycobacterium avim, Staphylococcus aureus, Streptococcus pyogenes, Pseudomonas pseudomallei, Clostridium tetani, Escherichia coli, Vibrio Fetus e Listeria monocytogenes (CAMPBELL, 1999).

Diante do exposto, pode-se constatar que são vários os fatores causadores de AT e adoecimento de trabalho no processamento de alimentos nos frigoríficos, e esses fatores podem ser objeto de pesquisas executadas por 
diferentes delineamentos e abordagens metodológicas, dentre as quais os estudos epidemiológicos que trazem importantes fontes de dados que possibilitam ao profissional da área de saúde do trabalhador correlacionar o perfil sóciodemográfico com as incidências das doenças e as condições socioeconômicas.

Minayo-Gomez e Thedim- Costa (2003), defende a idéia de que área do saber em saúde do trabalhador deve obedecer á transdisciplinaridade*, para que se criem as redes de referências, dentro e fora das empresas, onde o trabalhador possa fortalecer esse conhecimento em uma cadeia infindável de informações. Com esse maior esclarecimento voltado para esse trabalhador a autora acredita que alguns problemas poderiam ser amenizados e haver, conseqüentemente redução das estatísticas de acidentes e doenças do trabalho.

Assim, para o estudo ora apresentado, foi selecionado o método epidemiológico para investigar a morbidade pelo trabalho na indústria frigorífica.

\footnotetext{
* A transdisciplinaridade está ligada tanto a uma nova visão como a uma experiência vivida. É um caminho de autotransformação orientado para o conhecimento de si, para a unidade do conhecimento e para a criação de uma nova arte de viver (NICOLESCU, 1997, p.2.).
} 


\subsection{Geral}

Analisar a ocorrência de acidente de trabalho em uma indústria frigorífica.

\subsection{Específicos}

- Identificar o número de acidentes de trabalho;

- Caracterizar os acidentes de trabalho, seguindo as variáveis: tipo do acidente de trabalho, dias da semana, meses, ano, horário, sexo, idade dos trabalhadores, setor de trabalho e turno de trabalho;

- Identificar o tempo de trabalho perdido ocasionado pelos acidentes de trabalho;

- Identificar o custo econômico para a empresa dos dias de trabalho perdidos pelos trabalhadores vitimas de acidente de trabalho;

- Analisar a série histórica do coeficiente de acidentes de trabalho geral e específico, identificando os locais e atividade que apresentam maior risco. 
3 MATERIAL e MÉTODO 


\subsection{Delineamento da Pesquisa}

Estudo não experimental, descritivo quantitativo, epidemiológico baseado em dados secundários (CHECKOWAY PEARCE; KRIEBEL, 2004).

\subsection{Local}

Indústria de grande porte*, situada na cidade de Descalvado, no interior do Estado de São Paulo, classificada como indústria de abate de aves e outros pequenos animais e preparação de produtos de carne na Classificação de Atividades Econômicas, sob o número 15121 (BRASIL MF/IBGE, 2006) e considerada de grau de risco 3 (BRASIL MTE, 2000). Sua produção estimada é de 120 a 140 mil frangos/dia. O trabalho é organizado em setores denominados: aves, embutidos, granja, incubatório, fábrica de ração e expedição onde são realizadas atividades peculiares a cada etapa de produção.

\subsection{População}

A indústria contava em 2004 com 1039 trabalhadores e 2005 com 1066 trabalhadores. A população alvo desta pesquisa foi constituída pelos indivíduos que tiveram ocorrências anotadas nas Comunicações de Acidentes de Trabalho (CAT) registrados no Serviço Especializado de Segurança e Medicina do Trabalho

*Classificação das empresas segundo número de funcionários: 09 á 19 funcionários- Microempresa; 19 á 99 funcionários Pequena Empresa; 100 á 150 funcionários Média Empresa; Acima de 150 funcionários Grande Empresa; (SEBRAE, 2006) 
(SESMET) nos anos 2004 e 2005.

\subsection{Definição das Variáveis}

A variável dependente ou resposta principal, na estimação do risco, é dicotômica (sofreu ou não acidente), sendo algumas variáveis preditoras: sexo (dicotômica), idade (proporcional), tempo de atuação na empresa ou setor específico (proporcional), setor (politômica).

\subsection{Procedimentos}

Em dezembro de 2005 foi feito o levantamento das CATs do período de 2004 a 2005. O formulário da CAT foi usado como instrumento de coleta de dados e é apresentado no Apêndice 1. Os dados foram coletados pela autora da pesquisa, na própria indústria, sendo identificadas as características sóciodemográficas dos trabalhadores acidentados (idade, sexo, faixa salarial, tempo de empresa, estado de procedência, escolaridade e atividade profissional), a caracterização dos acidentes de trabalho (tipo de descrição, parte do corpo atingida, afastamentos e dias perdidos de trabalho) e, posteriormente, foi calculado o custo dos dias de trabalho perdidos. $\mathrm{O}$ cálculo do custo de um acidente de trabalho, (CA) foi obtido empregando-se a seguinte relação:

$$
C A=[1+0,65] \times\left(\frac{\text { salário base }}{30}\right) \times(\text { número dias afastados })
$$

ou seja, acrescentando-se 65\% (correspondentes aos encargos da empresa com o funcionário afastado, percentual específico para esse ramo empresarial) ao valor 
calculado, tendo-se como referência o salário-base do trabalhador acometido. O custo total dos acidentes no período é obtido pela somatória dos CA acima calculados.

Para analisar quantitativamente o risco de acidentalidade a que estiveram expostos os trabalhadores no período de 2004 a 2005 foi utilizado um indicador recomendado internacionalmente, a saber, o coeficiente de freqüência de acidentes, (CF), dado por:

$$
C F=\frac{\text { número de acidentes em certo período }}{\text { Horas }- \text { Homens trabalhadas neste período }} \times 10^{6}
$$

Esse indicador consiste, a rigor, em uma taxa, uma vez que, em seu numerador, tem-se o número de acidentes de trabalho registrados em certo período de tempo, como mês ou ano, ao passo que o denominador expressa o total de horas trabalhadas pelo conjunto de trabalhadores de um setor, empresa ou grupo de empresas no período considerado. O fator de multiplicação ou potência de $10\left(10^{6}=\right.$ 1000 000) serve para padronização, de tal sorte que empresas de diferentes tamanhos podem ser comparadas quanto ao risco de acidentalidade mensurado por esse indicador. É importante notar que alguns textos indicam que se considere, no numerador, apenas os acidentes que geraram afastamentos do ambiente de trabalho. No entanto, nesta análise serão considerados todos os acidentes registrados nas Comunicações de Acidente de Trabalho (CAT), nos anos 2004 e 2005, quer tenham resultado, ou não, em afastamentos, evitando-se, desse modo, subestimar o risco de acidentes na empresa.

Os dados foram transpostos para planilhas do programa Statiscal People Science Social (SPSS) e geraram tabelas e gráficos 


\subsection{Questões Éticas}

O projeto de pesquisa foi aprovado pelo Comitê em pesquisa com seres humanos da Escola de Enfermagem de Ribeirão Preto da Universidade de São Paulo (Anexo 1). 
4 RESULTADOS E DISCUSSÃO 


\subsection{Processos de trabalho, condições de trabalho - insalubridade e divisão do trabalho}

Inicialmente é apresentada a caracterização do ambiente de trabalho nos diferentes setores da indústria com a finalidade de descrever a situação de trabalho em cada um dos setores da empresa. Essas informações foram coletadas através de consulta ao mapa de risco da instituição, efetuada pelos profissionais do SESMET.

Setor das aves: local de trabalho destinado ao processamento de aves que vai da recepção à expedição do produto. No setor são executadas as seguintes atividades

a) Recepção: onde a matéria-prima chega para o início do processo de produção, o descarregamento das aves. As mesmas chegam dentro de gaiolas, ainda vivas, pela parte externa da indústria, onde os trabalhadores daquele setor manipulam a matéria-prima pelos pés, pendurando-as de cabeça para baixo na nória* (máquina giratória onde há ganchos para acoplar a matéria-prima), em seguida as mesmas passam por uma inspeção para detectar qualquer anormalidade física antes de dar andamento ao processo. Essa inspeção é realizada através de uma coluna, com luz fuorescente, e o ambiente permanece escuro para não causar estresse nas aves e não elevar mais a temperatura do ambiente.

Descrição da situação de trabalho: temperatura elevada, níveis elevados de ruído e iluminação, poeira, atividade repetitiva, exposição a material biológico (excreta de animais).

b) Abate/sangria: nesse setor as aves passam pelo processo de abate e/ou sangria,

\footnotetext{
* É uma máquina giratória com ganchos coloridos utilizados para pendurar o frango quando o mesmo vem do Chiller (Máquina utilizada para o processo de resfriamento do frango), como também quando vai ser abatido.
} 
algumas instituições utilizam-se do abate humanizado. Uma vez que as aves estão de cabeça para baixo, com uma pistola automática, perfuram artéria a e deixam sangrar até a morte.

Descrição da situação de trabalho: temperatura elevada, ruído elevado, atividade repetitiva, exposição a material biológico (sangue animal).

c) Escaldagem: após a fase anterior, as aves continuam penduradas na nória de cabeça para baixo, então são mergulhadas em tonéis com água em fervura, para retirada das penas. A retirada total das penas é completada com auxílio manual dos funcionários daquele setor que retiram o excesso com a mão.

Descrição da situação de trabalho: temperatura elevada, ruído elevado, poeira, atividade repetitiva.

d) Evisceração: ainda na nória a matéria prima começa a ser fragmentada para que cada parte seja encaminhada para seu destino final. Nesse setor, as aves passam por máquinas que possuem pressão a vácuo, onde todas suas vísceras são retiradas de uma só vez (serão encaminhadas e separadas como miúdos para o preparo de outras carnes), concomitante a essa atividade, funcionários executam atividades manuais, utilizando-se de facas, para retirada do pescoço e cloaca.

Descrição da situação de trabalho: ambiente com acondionamento, e temperatura mantida por volta de $25^{\circ} \mathrm{C}$, úmido, manuseio de objeto perfurante e cortante, presença de ruído elevado, exposição á materiais biológicos (vísceras e sangue).

e) Espostejamento/ sala de corte: nesse setor ocorre a desossa do frango (técnica utilizada para separar toda a carne do frango da carcaça) e os cortes em cubos, filés e frango inteiro sem osso para variados fins de industrialização. O 
funcionário pega o frango com as mãos que vem da sala de evisceração pela, nória*, coloca na mesa de corte para executar as técnicas.

Descrição da situação de trabalho: temperatura baixa, manuseio de objeto perfurante e cortante, ruído elevado e atividade repetitiva.

f) Embalagem: após a realização dos vários tipos de corte, as carnes são encaminhadas para o setor no qual serão acondicionadas em embalagens.

Descrição da situação de trabalho: temperatura baixa, manuseio de máquinas de prensa, ruídos, atividade repetitiva, uso de força em excesso de membro superior.

g) Embalagem final/túneis de congelamento: uma vez que as carnes estejam embaladas são encaminhadas para câmaras de congelamento através dos paletes (carrinho com quatro rodas, puxado a mão) e as empilhadeiras, onde as carnes embaladas são acondicionadas em caixas com grande quantidade de produtos.

Descrição da situação de trabalho: temperatura abaixo de zero grau centígrados, ruídos elevados, atividades repetitivas e com carga de peso elevada.

h) Expedição: local onde toda mercadoria pronta para ser comercializada é transferida de dentro da indústria para os caminhões de transporte.

\section{Setor das granjas}

A Granja está situada na zona rural em uma fazenda de 113 alqueires, sendo $80 \%$ de reserva florestal a $17 \mathrm{Km}$ da cidade de Descalvado-SP. Dispõe da seguinte infra-estrutura:

- portaria com guarita e rodolúvio, onde todo o veículo que entra é aspergido com 
solução desinfetante;

- estradas de intercomunicação entre os núcleos;

- escritório de administração;

- refeitório;

- fábrica de ração, com 1 misturador, 2 moinhos e 2 silos com capacidade de 170 toneladas;

- almoxarifado;

- marcenaria;

- oficina mecânica;

- colônia de empregados;

- dois poços artesianos: um com 2 caixas de 15000 litros, o outro poço está com duas caixas, com capacidade de 50.000 e 100000 litros respectivamente;

- possui 11 núcleos de cria/produção, onde cada um possui instalações com chuveiros para banho, sala de ovos e sala de fumigação, distantes dos galpões.

Cada galpão tem 125m de comprimento por 14m de largura com 3,50m de pé direito. Os galpões são subdivididos em 12 boxes de $10 \mathrm{~m} \times 14 \mathrm{~m}$, um box de $5 \mathrm{~m}$ x14m onde estão os controles das máquinas, relógio de luz, caixa de arraçoamento, balança e controle dos ventiladores.

No lado de fora, está o silo com capacidade para 6 toneladas. Os galpões possuem telhas de amianto, com lanternim, em seu interior há comedouros automáticos, bebedouros tipo calha, ventiladores e ninhos manuais. Todos os galpões são telados e cortinados e externamente são totalmente cercados por alambrado.

Todos os núcleos possuem uma composteira para as aves mortas.

a) Recria: local destinado para o crescimento e desenvolvimento das aves para 
futuro abate. Ambiente com pouca iluminação para evitar aumento da temperatura e estresse para as aves em desenvolvimento. Atividade realizada nesse local destina-se á realização de monitoramento da temperatura, iluminação, repor água e ração, acompanhar alimentação das aves, aplicar vacinas tópicas e intramusculares nas aves.

b) Produção de ovos: local destinado ao desenvolvimento dos ovos produzidos pelas aves matrizes. Os ovos que são selecionados na granja de matrizes são acondicionados em incubadoras próprias para o desenvolvimento embrionário da ave que tem seu ciclo finalizado no prazo de 21 dias. O funcionário desse setor realiza atividades de monitorizarão da temperatura da incubadora, acompanhamento do ciclo e aplicação de vacinas.

c) Seleção de ovos; local destinado a selecionar os ovos provindos de granjas diferentes para serem encaminhados para o processo de eclosão.

\section{Setor do incubatório}

\section{Realizam as seguintes atividades}

a) Recepção: O ovo já vem pré-selecionado do carrinho de coleta do galpão. Em seguida, são fumigados e acondicionados em uma sala a $21^{\circ} \mathrm{C}$ e $75 \%$ de umidade relativa, no núcleo de produção da granja de matrizes. Diariamente, no final da tarde, o caminhão do incubatório efetua a coleta em todos os núcleos. Os ovos chegam ao incubatório embalados em caixas plásticas de cor amarela. Cada caixa contém 8 bandejas totalizando, assim, 240 ovos.

b) Acondicionamento: para cada lote de matriz, adota-se uma cor de caixa e bandeja, recebendo sua identificação, facilitando-se a sua rastreabilidade até a 
saída do pinto.

O descarregamento das caixas de ovos é realizado com o auxilio de carrinhos transportadores ou paletes e imediatamente vão para a sala de ovos.

c) Incubação dos ovos; durante a fase de incubação, deve-se estar atento a uma série de fatores, tais como:

- antes do início da incubação, observar o funcionamento dos aquecedores e sistema de viragem;

- ter cuidado com o transporte de ovos para o interior das incubadoras, evitando-se, assim, choques contra portas e colunas;

- os funcionários devem ter habilidade para executar a tarefa de incubação com rapidez e precisão;

- a leitura de temperatura, umidade e viragem devem ser monitoradas de hora em hora, garantindo, assim, os níveis ótimos.

d) Sala dos pintinhos: a sala deve permanecer limpa e desinfetada, com a temperatura em torno de $25^{\circ} \mathrm{C}$ e com aproximadamente $55 \%$ de umidade relativa, com alta taxa de renovação de ar.

O saque é um nome dado para a retirada dos pintos das bandejas de eclosão, sendo observados em relação a anormalidades como: umbigo mal cicatrizado, falha de empenamento, bico torto e número anormal de membros. Os demais, em boas condições, seguem para a sala de vacinação.

f) Vacinação: depois da seleção, os pintos seguem por uma esteira, chegando à mesa vacinadora, onde são vacinados contra as doenças de Marek e Gumboro (MD-Lio Vac + Bursine $2 \mathrm{TC} \AA)$, via subcutânea, com agulha 25x8. A máquina vacinadora possui um sistema de contagem, onde os pintos são colocados em caixas plásticas em número de 50 , nas quais são separados por lote. A limpeza e 
desinfecção da sala são realizadas diariamente. As vacinadoras são limpas com detergente e, após a secagem, coloca-se um algodão com formol em seu interior.

\section{Setor fábrica de ração}

Realizam as seguintes atividades:

a) limpeza manual: a limpeza no local deve ser constante, pois devido à natureza da matéria-prima utilizada ocorre acúmulo de poeira, sendo necessário então a limpeza constante.;

b) armazenamento; Antes do armazenamento toda matéria - prima é secada, depois encaminha para a fornalha.;

c) carregamento e descarregamento de produtos; trabalho caracterizado pela sobrecarga de peso.;

d) acondicionamento: trabalho caracterizado pela sobrecarga de peso;.

e) moagem/mistura: trabalho automatizado, durante a operação, porém no encaminhamento da matéria-prima até os túneis para mistura, ocorre sobrecarga de peso;.

Esse setor deve ser limpo constantemente, devido ao acúmulo de poeira em conseqüência de farelos ali produzidos, trabalho exaustivo, devido ao intenso fluxo de matéria-prima com peso superior a $50 \mathrm{~kg}^{\star}$, que devem ser transportados. Aliado a todos esses fatores, a empresa que atua no mercado há mais de 20 anos, vem expandindo e, com isso, aumentando sua produtividade, que tem como matriz para o seu processo a produção de ração para o alimento das aves que serão abatidas futuramente. Essa ração tem que manter sua qualidade, para sobrevida das aves, uma vez que se ocorre falha nesse processo, há diminuição da matéria-

\footnotetext{
*Para Couto, 2002, não se deve carregar cargas com valor superior à 30 kg (p.305).
} 
prima e a priori diminuição da produtividade. Pode-se concluir então que, como a grande maioria das unidades, é um local que é influenciado por grande pressão no processo de trabalho

As atividades de trabalho executadas pelos trabalhadores nos setores ora descritos estão contempladas na Classificação Brasileira de Ocupação (CBO) (BRASIL MTE, 2002).

${ }^{1}$ Ajudante de abatedouro: código da classificação brasileira de ocupação-CBO 848.520

Descrição sumária: abatem bovinos e aves controlando a temperatura e velocidade de máquinas. Preparam carcaças de animais (aves, bovinos, caprinos, ovinos e suínos) limpando, retirando vísceras, depilando, riscando pequenos cortes e separando cabeças e carcaças para análises laboratoriais. Tratam vísceras limpando e escaldando. Preparam carnes para comercialização, desossando, identificando tipos, marcando, fatiando, pesando e cortando. Realizam tratamentos especiais em carnes, salgando, secando, prensando e adicionando conservantes. Acondicionam carnes em embalagens individuais, manualmente ou com o auxílio de máquinas de embalagem a vácuo. Trabalham em conformidade com as normas e procedimentos técnicos e de qualidade, segurança, higiene, saúde e preservação.

${ }^{2}$ Ajudante de serviços gerais: código da classificação brasileira de ocupação-CBO9914.

Descrição sumária: executam manutenções elétrica e hidráulica, substituindo, trocando, limpando, reparando e instalando peças, componentes e equipamentos. Realizam manutenção de carpintaria e marcenaria, consertando 
móveis, substituindo e ajustando portas e janelas, trocando peças e reparando pisos e assoalhos. Conservam alvenaria e fachadas e recuperam pinturas, impermeabilizam superfícies, lavando, preparando e aplicando produtos. Montam equipamentos de trabalho e segurança, inspecionando local e instalando peças e componentes em equipamentos. Executam serviços gerais em residências (troca de chuveiros, conserto de portas e janelas, entre outros). Trabalham seguindo normas de segurança, higiene, qualidade e proteção ao meio ambiente.

3. Ajudante de serviço de limpeza : código da classificação brasileira de ocupaçãoCBO 514225.

Descrição sumária: conservam a limpeza de logradouros públicos por meio de coleta de lixo, varrições, lavagens, pintura de guias, apara de gramas etc. Lavam vidros de janelas e fachadas de edifícios e limpam recintos e acessórios dos mesmos. Executam instalações, reparos de manutenção e serviços de manutenção em dependências de edificações. Atendem transeuntes, visitantes e moradores, prestando-lhes informações. Zelam pela segurança do patrimônio e das pessoas, solicitando meios e tomando providências para a realização dos serviços.

4. Ajudante da fábrica de embutidos: código da classificação brasileira de ocupaçãoCBO 848115.

Descrição sumária: preparam local de trabalho para processamento de alimentos, inspecionando ambiente, organizando e higienizando equipamentos e utensílios. Preparam máquinas para processamento de alimentos, selecionando, acoplando e desacoplando peças e utensílios, testando e regulando máquinas. Preparam fornos, matérias-primas e ingredientes. Processam produtos alimentícios, 
misturando, salgando e lavando carnes, embutindo e cozendo salsichas. Embalam e armazenam produtos alimentícios. Trabalham em conformidade com as normas e procedimentos técnicos e de qualidade, segurança, higiene, saúde e preservação ambiental.

5. Mecânico de manutenção: código da classificação brasileira de ocupação-CBO911305.

Descrição sumária: realizam manutenção em componentes, equipamentos e máquinas industriais; planejam atividades de manutenção; avaliam condições de funcionamento e desempenho de componentes de máquinas e equipamentos; lubrificam máquinas, componentes e ferramentas. Documentam informações técnicas; realizam ações de qualidade e preservação ambiental e trabalham segundo as normas de segurança.

6. Ajudante de núcleo: código da classificação brasileira de ocupação-CBO 623305.

Descrição sumária: preparam e higienizam instalações e equipamentos utilizados na criação; selecionam, manejam aves e coelhos e controlam sua sanidade; classificam e incubam ovos e realizam pequenas manutenções em instalações e equipamentos de aviário e coelhário.

7. Técnicos agropecuários: código da classificação brasileira de ocupaçãoCBO321110.

Descrição Sumária: prestam assistência e consultoria técnicas, orientando diretamente produtores sobre produção agropecuária, comercialização e procedimentos de biosseguridade. Executam projetos agropecuários em suas 
diversas etapas. Planejam atividades agropecuárias, verificando viabilidade econômica, condições climáticas e infra-estrutura. Promovem organização, extensão e capacitação rural. Fiscalizam produção agropecuária. Desenvolvem tecnologias adaptadas à produção agropecuária. Podem disseminar produção orgânica.

8. Controle da qualidade: código da classificação brasileira de ocupação-CBO 391205.

Descrição sumária: inspecionam o recebimento e organizam o armazenamento e movimentação de insumos; verificam a conformidade de processos; liberam produtos e serviços; trabalham de acordo com normas as e procedimentos técnicos, de qualidade e de segurança e demonstram domínio de conhecimentos técnicos específicos da área. Inspecionam o recebimento e organizam o armazenamento e movimentação de insumos; verificam a conformidade de processos; liberam produtos e serviços; trabalham de acordo com as normas e procedimentos técnicos, de qualidade e de segurança e demonstram domínio de conhecimentos técnicos específicos da área.

9. Auxiliar administrativo: código da classificação brasileira de ocupação-CBO 411005.

Descrição sumária: executam serviços de apoio nas áreas de recursos humanos, administração, finanças e logística; atendem fornecedores e clientes, fornecendo e recebendo informações sobre produtos e serviços; tratam de documentos variados, cumprindo todo o procedimento necessário referente aos mesmos; preparam relatórios e planilhas; executam serviços gerais de escritórios. 
10. Balconista: código da classificação brasileira de ocupação-CBO 521110.

Descrição sumária: vendem mercadorias em estabelecimentos do comércio varejista ou atacadista, auxiliando os clientes na escolha. Registram entrada e saída de mercadorias. Promovem a venda de mercadorias, demonstrando seu funcionamento, oferecendo-as para degustação ou distribuindo amostras das mesmas. Informam sobre suas qualidades e vantagens de aquisição. Expõem mercadorias de forma atrativa, em pontos estratégicos de vendas, com etiquetas de preço. Prestam serviços aos clientes, tais como: troca de mercadorias; abastecimento de veículos; aplicação de injeção e outros serviços correlatos. Fazem inventário de mercadorias para reposição. Elaboram relatórios de vendas, de promoções, de demonstrações e de pesquisa de preços.

11. Porteiro: código da classificação brasileira de ocupação-CBO 517405.

Descrição sumária: zelam pela guarda do patrimônio e exercem a vigilância de fábricas, armazéns, residências, estacionamentos, edifícios públicos, privados e outros estabelecimentos, percorrendo-os sistematicamente e inspecionando suas dependências, para evitar incêndios, roubos, entrada de pessoas estranhas e outras anormalidades; controlam fluxo de pessoas, identificando, orientando e encaminhando-as para os lugares desejados; recebem hóspedes em hotéis; escoltam pessoas e mercadorias; fazem manutenções simples nos locais de trabalho.

12. Encarregado de manutencão: código da classificação brasileira de ocupaçãoCBO 910105.

Descrição sumária: supervisionam as manutenções preventiva e preditiva, 
corretiva e emergencial de máquinas e equipamentos industriais, comerciais e residenciais; estabelecem indicadores de qualidade da manutenção; coordenam a construção de equipamentos para linha de produção de máquinas e equipamentos; elaboram documentação técnica; administram recursos humanos e financeiros, e trabalham de acordo com normas as de segurança.

13. Ajudante de eletricista: código da classificação brasileira de ocupação-CBO 951105

Descrição sumária: planejam serviços de manutenção e instalação eletroeletrônica e realizam manutenções preventivas, preditivas e corretivas. Instalam sistemas e componentes eletroeletrônicos e realizam medições e testes. Elaboram documentação técnica e trabalham em conformidade com normas e procedimentos técnicos e de qualidade, segurança, higiene, saúde e preservação ambiental.

Para a execução das atividades de trabalho, nos diferentes setores da indústria, os trabalhadores adotam diferentes posturas corporais que exigem freqüentes flexões do tronco, carregam peso, executam movimentos repetitivos, estão em contato com material biológico, principalmente sangue, porém, a necessidade da manutenção da temperatura do ambiente entre 12 a $15^{\circ} \mathrm{C}$ é o fator que parece mais preocupar os trabalhadores e a gerência no ambiente de trabalho nas indústrias frigoríficas. (FUNDACENTRO, 1991)

A baixa temperatura é necessária para garantir que a carne de ave processada preserve suas qualidades biológicas, evitando a contaminação e agravos à saúde do consumidor. Para tal, as empresas frigoríficas devem atender a NR-6 (BRASIL MTE, 2001) que respalda o trabalhador em relação ao uso de 
equipamento de proteção individual (EPI), a NR-17 (BRASIL MTE, 2002) que regulariza as condições ergonômicas no trabalho, NR-15 anexo 9 (BRASIL MTE, 1990) referente ás Atividades e Operações Insalubres, Artigo 253 da Consolidação das Leis Trabalhistas CLT (BRASIL. Decretos-Leis, 1943), Lei 6514 de 22 de dezembro de 1977, que definem as condições de trabalho para atividades em câmaras frias, bem como os intervalos para descanso. Porém, segundo Griefahn (2000), as leis que respaldam essa categoria de trabalhadores definem os parâmetros de temperaturas extremas com dados subjetivos, não podendo assim apostar em sua fidedignidade em relação à prevenção da saúde do trabalhador.

Diante de tal diversidade, a Convenção 155 da Organização Internacional do Trabalho (GALLOIS, 2002), da qual o Brasil é signatário, proporcionou alteração da NR-9 (BRASIL MTE, 1978), normalizando os limites de tolerância para exposição ao frio intenso. Outras organizações como a International Organization for Standardization (ISO-110779/93) adotou o Isolamento Requerido de Roupa (IREQ), que, juntamente com a American Conference of Govermmental Indústrial Hygienists (ACGIH) adotaram critérios (INTERNATIONAL ORGANIZATION FOR STANDARDIZATION - ISO, 1993) de acordo com a temperatura na qual o trabalhador está exposto, para o uso de medidas de proteção, descritos por GALLOIS,(2002,p.95) quais sejam:

- temperatura inferior a sete graus Celsius - fornecimento de luva;

- temperatura inferior a quatro graus Celsius - fornecimento de vestimentas adequadas;

- temperatura inferior a menos sete graus Celsius existência de abrigo aquecido;

- temperatura inferior a menos $12^{\circ} \mathrm{C}$ supervisão do estado físico do 
trabalhador

Para Gallois, (2002), apesar de toda legislação vigente, ainda ocorrem falhas na fiscalização dos frigoríficos e no conhecimento dos profissionais da área de saúde e segurança do trabalho e o adoecimento pelo trabalho realizado em baixas temperaturas é evidenciado.

Segundo Goldsmith (1989), a exposição ao frio pode interferir nas funções cerebrais incapacitando os membros, sendo que os principais sintomas poderiam ser evidenciados pela confusão mental e a dificuldade na coordenação, manifestações de paralisia e imprecisão dos movimentos. Algumas doenças como aquelas relacionadas aos distúrbios articulares, artrites e reumatismos no nível de membros, têm relação direta com os efeitos do frio no ambiente de trabalho (HALDER 2001).

Ambientes onde a temperatura é igual ou inferior a $15^{\circ} \mathrm{C}$ diminuem a perda da habilidade manual como conseqüência da diminuição da sensibilidade dos dedos e flexibilidade da juntas (GALLOIS, 2002).

No entanto, além dos fatores ambientais, maior atenção deveria ser direcionada á organização do trabalho nas indústrias frigoríficas, pois as atividades executadas nesse setor são caracterizadas pela fragmentação do trabalho, sujeitas á cadência imposta pelas máquinas e pela necessidade da produção e envoltas a pressões de tempo, não permitindo que os trabalhadores tenham controle sobre o seu trabalho. Dessa forma, os trabalhadores não têm a possibilidade de tomar decisões, como a escolha do ritmo e modo de execução do trabalho, a diminuição da cadência ou o momento de pausas quando necessárias (MALCHAIRE, 2001). 


\title{
4.2 Acidentes de trabalho
}

A Lei $n^{\circ} 8$ 213, de 24 de julho de 1991, inicialmente regulamentada pelo Decreto $n^{0}$ 357, de 7 de dezembro de 1991, posteriormente revogada pelo Decreto n 611, de 21 de julho de 1992 (Plano de Benefícios da Previdência Social), considera:

\begin{abstract}
...acidente do trabalho típico é o evento único, bem configurado no tempo e no espaço, de conseqüências geralmente imediatas, que ocorre pelo exercício do trabalho, acarretando lesão física ou perturbação funcional, resultando em morte ou incapacidade para o trabalho (temporário ou permanente total ou parcial). Sua característica depende do estabelecimento de nexo causal entre o acidente e o exercício do trabalho. A relação de causalidade não exige prova de certeza, bastando o juízo de admissibilidade. Nos períodos destinados a refeição ou descanso, ou por ocasião da satisfação de outras necessidades fisiológicas, no, local do trabalho ou durante este, o empregado é considerado no exercício do trabalho (MENDES, 1995, p.437).
\end{abstract}

Acidente de trajeto, ou "de percurso", ou in itinere, é o que ocorre no percurso da residência para o local de trabalho, ou deste para aquela, qualquer que seja o meio de locomoção. Interpretações reiteradas dadas pelo Poder Judiciário vêm firmando que apenas alterações relevantes do trajeto, para satisfação de interesses meramente pessoais, tiram a característica de etiologia com o trabalho para eventuais acidentes (MENDES, 1995, ,p.437).

Os acidentes de trabalho, típico e de trajeto são de notificação compulsória, sendo notificado através da Comunicação de Acidente de Trabalho (CAT). Esse instrumento de notificação pode ser emitido pela própria empresa onde o trabalhador atua, pelos serviços de saúde, sindicatos e pelo próprio trabalhador. A emissão da CAT é de ordem legal, significando o direito do trabalhador ao seguro acidentário e o reconhecimento oficial do acidente (WUNSCH FILHO, 1999).

Investigando-se a situação acidentária no frigorífico, no biênio estudado, constatou-se o registro de $135(12,66 \%)$ trabalhadores acidentados no trabalho 
dentre os 1066 trabalhadores expostos, sendo que dois desses trabalhadores sofreram mais de um AT, assim a população alvo foi constituída pela comunicação de 137 AT, registrados nas CATs, sendo 134 (97,8\%) acidentes típicos e três (2,2\%) acidentes de trajeto. A Tabela 1 mostra a distribuição dos acidentes de trabalho.

Tabela - 1 Distribuição dos Acidentes de Trabalho, segundo o tipo de acidente, afastamento e turno de trabalho. Descalvado - SP, . 2004-2005 (n=137)

\begin{tabular}{lcc}
\hline $\begin{array}{c}\text { Tipo de Acidente de } \\
\text { Trabalho }\end{array}$ & $f$ & $\%$ \\
\hline \hline Típico & 134 & 97,8 \\
Trajeto & 03 & 2,2 \\
Total & 137 & 100 \\
& & \\
Afastamento & 102 & 74,5 \\
Sim & 35 & 25,5 \\
Não & 137 & 100 \\
Total & & \\
& & \\
Turno de Trabalho & 65 & 47,4 \\
Matutino & 38 & 27,7 \\
Vespertino & 34 & 24,8 \\
Noturno & 137 & 100,0 \\
\hline \hline Total & & \\
\hline \hline
\end{tabular}

Dos 137 AT, 102 (74,5\%) ocasionaram afastamento do trabalho e, no turno matutino, foi registrada a maior freqüência dos AT (65), correspondendo a $47,4 \%$ do total de AT.

Em relação ao turno de trabalho, Fischer, (1984) constatou em estudos observacionais que o trabalho noturno apresentou redução no número de acidentes de trabalho, apresentando alguns aspectos favoráveis como a redução das atividades laborais perigosas, redução de materiais e pessoal.

Outros autores com Hildebrandt (1987), dentre vários estudos, 
evidenciaram aumento de erros e acidentes do trabalho durante certos períodos do dia e da noite.

Esse resultado também foi evidenciado neste estudo, uma vez que se constatou o predomínio dos acidentes de trabalho no turno matutino $(47,4 \%)$. A esse fato justifica-se pela existência de fluxo de pessoal do setor administrativo, supervisores da indústria, inspeções e auditorias que ocorrem no período matutino, aumentando a pressão no processo de trabalho.

Na literatura, é evidenciada a subnotificação do registro de AT em vários setores, mesmo diante da atribuição legal da CAT. Muitas empresas e trabalhadores só notificam os acidentes graves, que causam afastamento e necessitam de atendimento médico-especializado. Binder et al. (2003), estudando o registro de acidentes de trabalho típicos em posto de atendimento da previdência social no município de Botucatu-SP, constataram que as empresas subnotificaram grande parte dos acidentes e todas as CATS emitidas estavam relacionadas a AT com período de afastamento superior a 15 dias.

A Constituição Federal (CF) de 1988 (BRASIL,1988) estabelece a competência da União para cuidar da segurança e da saúde do trabalhador por meio das ações desenvolvidas pelos Ministérios do Trabalho e Emprego, da Previdência Social e da Saúde, atribuições regulamentadas na Consolidação das Leis do Trabalho (Capítulo V, do Título II, lei n.6.229/75), nas Leis n 8.212/91 e 8.213/91, que dispõem sobre a organização da seguridade social e institui planos de custeio e planos de benefícios da previdência social e na Lei Orgânica da Saúde, Lei № 8080/90 (BRASIL MPS, 2004, p.5).

Dentre essas disposições sobre o plano de custeio, a legislação assegura ao trabalhador, com afastamento superior a 15 dias, um salário que tem seu cálculo 
baseado em seu tempo de contribuição previdenciária e a descrição e/ou gravidade do acidente. Sendo assim, as empresas apresentam interesse maior em registrar os acidentes seguidos de afastamento superior a 15 dias, pois a partir do $16^{\circ}$ dia, não possuí mais obrigações de pagamentos ou ressarcimentos a esse trabalhador.

Os poderes da União, estabelecendo, também, os poderes remanescentes dos Estados e dos Municípios, definem que a União organiza, mantém e executa a inspeção do trabalho, com exclusividade (artigo 21, XXIV) e legisla, privativamente, sobre direito do trabalhador (artigo.22, I). A União, os Estados, o Distrito Federal e os Municípios cuidam da saúde e assistência pública, da proteção e garantia das pessoas portadoras de deficiência (artigo.23, II). A União, os Estados e o Distrito Federal legislam concorrentemente sobre previdência social, proteção e defesa da saúde (BRASIL MPS, 2004, p.5).

\section{Características da população trabalhadora vitimada pelo AT}

A Tabela 2 apresenta a caracterização da população de trabalhadores que foi vitimada por AT no período estudado segundo dados sóciodemográficos. 
Tabela 2 - Distribuição dos trabalhadores acidentados, segundo faixa etária, estado civil, sexo e salário. Descalvado - SP, 2004-2005 ( $n=135)$

\begin{tabular}{lccc}
\hline \multicolumn{1}{c}{ VARIÁVEIS } & $\mathbf{f}$ & & $\%$ \\
\hline Faixa etária(anos) & & 54 & 40,0 \\
& até 24 & 56 & 41,0 \\
& $25-30$ & 21 & 15,6 \\
& $41-59$ & 01 & 0.7 \\
Total & 60 ou mais & 03 & 2,2 \\
& Faltante & 135 & 100 \\
Estado Civil & & 59 & 43,7 \\
& Casado & 63 & 46,7 \\
& Solteiro & 01 & 0.7 \\
Total & União Consensual & 01 & 0.7 \\
& Divorciado & 11 & 8,1 \\
Sexo & Não se aplica & 135 & 100 \\
Total & & 108 & 80,0 \\
Renda Familiar (em Reais) & Masculino & 27 & 20,0 \\
& Feminino & 135 & 100 \\
& & 97 & 71,9 \\
& $301-600$ & 31 & 23,0 \\
& $601-900$ & 06 & 4,4 \\
\hline \hline
\end{tabular}

As 137 notificações envolveram, 135 trabalhadores. A faixa etária de maior prevalência foi a de 25 a 40 anos de idade, com uma freqüência de 56 (41,5\%). A média entre as idades foi de 30,20 anos, mediana 28,00 anos e desvio padrão de 9,77 anos, considerando a menor idade de 18 anos e a maior de 73 anos.

Quanto ao estado civil, 59 (43,7\%) dos trabalhadores acidentados são casados com predomínio do sexo masculino com freqüência de 108 (80\%).

Sobre a distribuição de renda familiar, foram identificados que 97 (71,9\%) dos trabalhadores acidentados recebem entre a faixa salarial de $R \$ 301,00$ a $R \$$ 
600,00 , mensalmente. Apresentando média de $\mathrm{R} \$ 572,74$, mediana de $\mathrm{R} \$ 535,60$ e desvio padrão de $\mathrm{R} \$ 263,46$, tendo como base o menor salário de $\mathrm{R} \$ 339,95$ e 0 maior salário de $\mathrm{R} \$ 2$ 900,00.

A Tabela 3 apresenta os dados relativos à caracterização da população de trabalhadores que foram vitimados por AT no período estudado, segundo suas atividades laborais.

Tabela - 3 Distribuição dos trabalhadores acidentados, segundo a ocupação* e/ou profissão. Descalvado - SP, 2004-2005 (n=135)

\begin{tabular}{lcc}
\hline \hline Ocupaçãolprofissão & $\boldsymbol{f}$ & $\%$ \\
\hline \hline Ajudante de abatedouro & 84 & 62,22 \\
Ajudante de serviços gerais & 13 & 9,6 \\
Ajudante de serviços de & 09 & 6,67 \\
limpeza & & \\
Ajudante de fábrica de & 08 & 5,94 \\
embutidos & & \\
Mecânico de manutenção & 08 & 5,94 \\
Ajudante de núcleo & 03 & 2,22 \\
Técnico agropecuário & 03 & 2,22 \\
Auxiliar controle da qualidade & 02 & 1,49 \\
Auxiliar administrativo & 01 & 0,74 \\
Balconista & 01 & 0,74 \\
Porteiro & 01 & 0,74 \\
Encarregado de manutenção & 01 & 0,74 \\
Ajudante de eletricista & 01 & 0,74 \\
\hline \hline Total & 135 & 100,0 \\
\hline *A categorização usada baseou-se no Código Brasileiro de Ocupações-CBO (BRASIL, 2002).
\end{tabular}

Os dados da Tabela 3 mostram que 84 (62,22\%) dos trabalhadores vitimados por AT exercem atividades de ajudante de abatedouro, 13 ajudantes de serviços gerais (9,6\%), 9 de ajudantes de serviço de limpeza (6,67\%), 8 de ajudantes de fábrica de embutidos $(5,94 \%)$ e em igual número mecânico de manutenção (5,94\%), seguidos por freqüências menores de outras ocupações. 
Segundo a descrição sumária da classificação brasileira de ocupaçõesCBO848. 520 (BRASIL,2002), a atividade do ajudante de abatedouro é caracterizada pelo abate de bovinos e aves, controle da temperatura e velocidade de máquinas, preparo de carcaças de animais (aves, bovinos, caprinos, ovinos e suínos), limpando, retirando vísceras, depilando, cortando e separando cabeças e carcaças para análises laboratoriais. Os trabalhadores tratam vísceras limpando e escaldando-as, preparam carnes para comercialização desossando, identificando tipos, marcando, fatiando, pesando e cortando, realizam tratamentos especiais em carnes, salgando, secando, prensando e adicionando conservantes. Acondicionam carnes em embalagens individuais, manualmente, ou com o auxílio de máquinas de embalagem a vácuo. Trabalham em conformidade com as normas e procedimentos técnicos e de qualidade, segurança, higiene, saúde e preservação.

\section{Local, atividade de trabalhador e a ocorrência de AT}

Na Tabela 4 apresenta-se a caracterização da população de trabalhadores que foram vitimados por AT, no período estudado, segundo os setores que compõem a empresa. 
Tabela 4 - Distribuição dos trabalhadores acidentados, segundo setor de atividades. Descalvado-SP, 2004-2005 ( $\mathrm{n}=135)$.

\begin{tabular}{llcc}
\hline Variáveis & Setor & $\boldsymbol{f}$ & $\%$ \\
\hline \hline Unidade de aves & Sala de cortes & 29 & 21,48 \\
& Expedição & 25 & 18,52 \\
& Plataforma de aves & 12 & 8,89 \\
& Evisceração & 09 & 6,67 \\
& Higienização & 08 & 5,93 \\
& Escaldagem & 04 & 2,96 \\
& Saída de produtos & 02 & 1,48 \\
& condenados & & \\
Unidade de embutidos & Embalagem & 08 & 5,93 \\
& Embutidos & 04 & 2,96 \\
& Salsicharia & 04 & 2,96 \\
Unidade de serviços auxiliares & Oficina de manutenção & 04 & 2,96 \\
& Portaria Abatedouro & 01 & 0,74 \\
& Pátio almoxarifado & 01 & 0,74 \\
& Flotador & 01 & 0,74 \\
& Controle da qualidade & 01 & 0,74 \\
Unidade de vendas & Lavanderia & 01 & 0,74 \\
Total & Cozinha do refeitório & 01 & 0,74 \\
\hline \hline & Granja & 06 & 4,44 \\
Unidade das granjas e incubatório & Incubatório & 02 & 1,48 \\
& Fábrica de ração & 08 & 5,93 \\
& Loja de aves e ovos & 01 & 0,74 \\
\hline \hline
\end{tabular}

A unidade de aves, que contempla os seguintes setores: sala de cortes, evisceração, escaldagem, expedição, plataforma de aves vivas, saída de produtos condenados e higienização, destacou-se dentre as demais unidades em decorrência da maior porcentagem de acidentes de trabalho, 89 indivíduos acidentados $(65,93 \%)$, distribuídos pelos diversos setores. Constatou-se que os setores da sala de corte com 29 (32,58 \%) e expedição com 25 (28,09\%) foram os locais onde os acidentes mais freqüentemente ocorreram.

Em sua maioria, as atividades executadas na indústria frigorífica são fixas 
e pouco variáveis, com ciclos de trabalho muito curtos, ocasionando alta repetitividade. Estudos confirmam que essa forma de trabalho apresenta aspectos nocivos que são potencializados por outros fatores, como as posturas corporais, principalmente, a utilização de força nas tarefas que aumentam os riscos para acidentes (OCCUPATION SAFETY AND HEALTH -OSHA, 2004).

Acrescido a esse fato, o ruído produzido pelas máquinas e equipamentos da unidade, geralmente acima de $80 \mathrm{~dB}$, podem interferir na concentração da atenção e conseqüentemente a ocorrência de AT como descreve Malchaire (1995), que considera as atividades com exigência de destreza, quando efetuadas em ambiente com ruído elevado, são realizadas com esforço maior, potencializando assim a ocorrência de acidentes.

Além do ruído, os espaços de trabalho e as disposições de mesas de trabalho podem ser considerados como fatores predisponentes aos AT nessa situação de trabalho. A Portaria no 210 do Ministério da Agricultura, (Anexo 1) (BRASIL MA, 1998, p.25) descreve que

\begin{abstract}
“....todas as operações que componham a evisceração e ainda a inspeção de linha deverão ser executados ao longo dessa calha, cujo comprimento deverá ser no mínimo de um metro por operário para atender a norma de execução dos trabalhos que nela se desenvolvem, a saber: cortes da pele do pescoço e traquéia; extração de cloaca; abertura do abdômen; eventração (exposição das vísceras); inspeção sanitária; retirada das vísceras; extração dos pulmões; "toilette" (retirada do papo, esôfago, traquéia etc.); lavagem final (externa e internamente)".
\end{abstract}

Ainda, em relação aos dados apresentados na Tabela 4, em outras unidades da empresa, embora com menor ocorrência, foram registrados AT na: fábrica de embutidos, onde 16 (11,85\%) indivíduos foram acidentados, unidade de serviços auxiliares com $10(7,41 \%)$ trabalhadores acidentados, unidade de granja e incubatório com 8 (5,93\%) vítimas e fábrica de ração onde 8 (5,93\%) trabalhadores tiveram AT registrados. 
A Tabela 5 apresenta a caracterização dos acidentes de trabalhadores que foram registrados no período estudado segundo o diagnóstico, dias de afastamento e agente causador.

Tabela- 5 Distribuições dos acidentes de trabalho, segundo o diagnóstico*, dias de afastamento e agente causador descritos na CAT. Descalvado-SP,. 2004$2005(n=137)$.

\begin{tabular}{lcc}
\multicolumn{1}{c}{ Diagnóstico(CID-10) } & $f$ & $\%$ \\
\hline \hline S00-S99 & 22 & 16,06 \\
M00-M99 & 15 & 10,95 \\
W00-W99 & 11 & 8,03 \\
T00-T99 & 03 & 2,19 \\
Y00-Y99 & 01 & 0,73 \\
Faltantes & 85 & 62,04 \\
Afastamento & & \\
Até 15 dias & 118 & 86,1 \\
16 dias ou mais & 02 & 1,5 \\
Faltantes & 17 & 12,4 \\
& & \\
Agente Causador & & 42,3 \\
Instrumento de trabalho & 58 & 39,4 \\
Ambiente & 54 & 16,8 \\
Mobiliário & 23 & 1,5 \\
Faltante & 02 & 100,0 \\
\hline \hline Total & 137 & dassificação Internacional das \\
\hline * As causas diagnósticas foram & classificadas segundo a & \\
Doenças(CID) & &
\end{tabular}

Constatou-se que em 85 CATs $(62,04 \%)^{*}$ não constava à descrição da conseqüência do acidente de trabalho. Dentre as informações registradas constatouse que em $22(16,06 \%)$ das CATs a conseqüência foi traumatismo superficial de cabeça e outros traumatismos não especificados do tornozelo e do pé (SOO-

\footnotetext{
*A descrição das conseqüências dos acidentes nas CATs revelam pouca atenção dos profissionais do SESMET da empresa na valorização dessas informações que são essenciais para o planejamento de estratégias preventivas á ocorrência de AT.
} 
S99), em 15 (10,95\%) registros foram as doenças do sistema osteomuscular e do tecido conjuntivo ( M00-M99), em 11 (8,03\%) AT a conseqüência foram outras causas externas de traumatismos acidentais (W00-W19); exposição a forças mecânicas inanimadas (W20-49); exposição a forças mecânicas animadas (W50-W64); outros riscos acidentais á respiração (W75-W84); exposição a corrente elétrica, a radiação e a temperaturas e pressões extremas do ambiente de trabalho (W85-W99), em $3(2,19 \%)$ foram os traumatismos superficiais envolvendo múltiplas regiões do corpo ( T00-T99) e em 1 (0,73\%) registro foi envenenamento (intoxicação) por e exposição a pesticidas com intenção não determinada (Y00-Y99).

Os traumatismos obtiveram o maior número de ocorrência de AT. Dentre esses os traumatismos mais evidenciados foram:

- S22. 9 -fratura dos ossos do tórax, parte não especificada, que apareceu apenas em uma CAT, registrada para um acidente que ocorreu na plataforma de aves vivas, devido à queda do trabalhador por piso escorregadio. Tipo de acidente característico nesse setor, que é também conhecido como recepção de aves, recebendo as aves vivas, para o processo de abate. O piso do local apresenta-se freqüentemente molhado devido à manutenção de higiene, para eliminar as fezes expelidas pelas aves.

- S52. 8 -fratura de outras partes do antebraço, que apareceram em três CATs, registradas para acidentes que ocorreram nos setores de expedição, sala de cortes $1^{0}$ turno, e escaldagem $2^{\circ}$ turno. As causas foram seguidas de compressão e fratura do antebraço dos funcionários da manutenção, durante o conserto da engrenagem e dispositivo de transmissão de uma máquina e queda dos demais que eram ajudantes de abatedouro, totalizando 58 dias de 
afastamento distribuídos pelos acidentados. Tipo de acidente característico para esta atividade profissional porque, durante toda sua jornada de trabalho, o trabalhador é solicitado a comparecer nos diversos setores da produção para o conserto dos maquinários. Nessa situação, a falta de comunicação e TLT (treinamento no local de trabalho), identificação visual dos locais de risco representam importantes fatores de risco para os acidentes, pois as máquinas devem ser paradas durante o conserto e manutenção das mesmas. Porém, devido ao ruído local produzido por várias máquinas trabalhando ao mesmo tempo, há a impossibilidade de comunicação fluente e a falta de conhecimento da rotina de trabalho por parte de funcionários novos que culminam em situação de acidente, na qual o funcionário, muitas vezes, liga a máquina antes do serviço de manutenção ter finalizado, acarretando traumas e lacerações severas ou até mesmo amputações de membros.

Os requisitos exigidos pela atual legislação brasileira, Lei 6.514 e Portaria 3.214 do Ministério do Trabalho - Norma Regulamentadora 12 (NR 12), determina a adoção de medidas de prevenção fundamentadas nessa legislação que definem as Condições de Trabalho na Operação de Prensas (MARTARELLO, MAGRINI,1989 p 267).

- S60 -traumatismo superficial do punho e da mão, que apareceram em seis CATs, registradas para os acidentes que ocorreram nos setores como fábrica de ração, sala de cortes $2^{\circ}$ turno, evisceração $1^{\circ}$ turno e embalagem $1^{\circ}$ turno. Descritos pelas seguintes situações: corte, laceração e feridas contusas, devido a impacto com objeto cortante; com predomínio de comprometimento em mão esquerda e dedos anular, indicador e médio totalizando assim 41 dias de afastamento, distribuídos entre os acidentados. Esse tipo de traumatismo é 
característico desse tipo de atividade profissional, dentre o qual se pode listar infinitas atribuições, para a causalidade do fenômeno, sendo uma delas as condições de trabalho, incluindo os objetos de trabalho. O principal objeto de trabalho utilizado por esses trabalhadores são as facas que, para maior segurança e prevenção de acidentes, devem ser amoladas todos os dias, como também devem ser oferecidas luvas de aço que impedem os cortes e lacerações. Há, porém, como em todas as situações, a barreira econômica que muitas vezes impede melhor e adequada segurança a esses trabalhadores. Santos (1989 p.179) afirma que em nenhuma empresa são realizadas atividades de manutenções preventivas e preditivas do conjunto de máquinas e equipamentos, ocorrendo habitualmente a manutenção corretiva e em determinadas empresas faz-se a preventiva sob a ótica da preservação dos meios de produção. Diante desse cenário, os trabalhadores vitimizados ficam incapacitados parcialmente, ou temporariamente, sem muitas vezes respaldo legal que possam atribuir aos acidentes ocorridos às inúmeras causas externas de competência do empregador e do sistema industrial como um todo e não culpabilizar o trabalhador pelo ocorrido, como se encontra nas descrições das comunicações de acidente de trabalho.

\footnotetext{
...pautado pela racionalidade da ordem econômica dominante, ausenta-se na redefinição das regulações contratuais e salariais anteriores e nem mesmo consegue desempenhar seu papel na compensação das desigualdades e fragilidades sociais, bem com na reparação das injustiças. Um Estado que, frente ao enorme contingente do moderno exército industrial de reserva gerado pelo desemprego em massa, oferece, quando muito, alternativa de re-inserção circunstancial negociadas com as empresas, por meio de incentivos financeiros e redução ou isenção de encargos sociais. (NAVARRO apud MINAYO \& COSTA, 1999, p.413).
}

- S61 -ferimento do punho e da mão, que aparece em sete CATs registradas para os acidentes que ocorreram nos setores da evisceração no $1^{\circ}$ e $2^{\circ}$ turno, sala de cortes $1^{\circ}$ e $2^{\circ}$ turno, expedição $2^{\circ}$ turno, manutenção $1^{\circ}$ turno e fábrica de 
ração $2^{\circ}$ turno. Seguidos de cortes, lacerações com feridas contusas, comprometendo mão direita e dedos indicadores e polegares, causados por facas, serras e colisão contra máquinas, totalizando 52 dias de afastamento distribuídos entre os acidentados.

- S62. 6 -fratura ao nível do punho e da mão aparece apenas em uma CAT, cujo AT ocorreu na sala de cortes devido à colisão do funcionário com algumas embalagens, causando fratura na base do dedo anular da mão esquerda, totalizando o afastamento de 60 dias do trabalhador do serviço. Analisando a situação, pode-se inferir o quão desconfortável torna-se a rotina de vida desse trabalhador supondo que o mesmo exercia suas atividades laborais dentro das normas exigidas pela organização. Em relação ao acidente em si, identificam-se três situações peculiares em que esse trabalhador está exposto. A primeira delas seria em relação ao sentimento de culpa pelo acidente e o medo de ser punido com a demissão. Seligmann (1986) caracteriza esse tipo de sentimento com a síndrome depressiva associada ao trabalho expresso com amargura ou revestido por conformismo fatalista. Associado a essa definição, citada também por Galbraith (1992), a cultura do contentamento que espera que cada trabalhador participe não somente do esforço conjunto, mas de um contentamento geral sobre as metas fixadas pela empresa, independentemente do que elas possam proporcionar.

A segunda situação seria pelo número de dias de afastamento, que implica em receber auxílio-doença pelo INSS, o processo para receber o benefício do INSS descreve os seguintes passos: o trabalhador deve comunicar á empresa (no departamento pessoal), através do atestado médico, seu afastamento superior a 15 dias. A empresa tem o prazo de 10 dias, contanto a data a partir da entrega do 
atestado, para emissão das devidas declarações, para que o funcionário com prazo de trinta dias (a partir da data do afastamento) possa encaminhá-los para o posto mais próximo de atendimento do INSS. Assim que essa etapa for concluída, o órgão referido irá agendar a primeira perícia com o médico perito, pois, somente após a primeira consulta, é que o segurado da previdência social, passa a receber o benefício de auxílio doença.

A terceira situação seria o comprometimento físico causado pelo acidente que gera situação estressora a esse indivíduo que irá passar por um processo de hospitalização e procedimentos cirúrgicos, permanecendo incapacitado e convalescente, inseguro em relação ás condições que irá encontrar no retorno a sua rotina diária no trabalho e no domicílio. Diante do quadro descrito, avalia-se o quão penoso e sofrido é para o trabalhador acidentar-se com a real estrutura previdenciária, judiciária e assistencial estabelecidas no país.

- S81. 9 -ferimento da perna, parte não especificada, com apenas um registro, devido ao acidente ocorrido no setor do almoxarifado pelo ajudante de serviços de limpeza que colidiu com o carrinho de limpeza, apresentando ferimento na perna devido ao corte, totalizando sete dias de afastamento.

- S83. 5 -entorse e distensão envolvendo ligamento cruzado (anterior) (posterior) do joelho, com registro de quatro CATs, devido aos acidentes ocorridos nos setores da granja e plataforma de aves vivas e lavanderia no $2^{\circ} \mathrm{e}$ $1^{0}$ turnos respectivamente, com a descrição de transferência de mobiliário (banco) de lugar, manuseio do guincho de gaiolas e queda devido ao piso escorregadio, atingindo joelho e tornozelo direito, comprometidos por um entorse e distensão envolvendo ligamentos, totalizando 27 dias de afastamento, distribuídos respectivamente entre os acidentados. 
- M62. 6 - distensão muscular, registrada apenas em uma CAT, devido ao acidente ocorrido na plataforma de aves vivas, pelo ajudante de produção, descrito por queda devido a piso escorregadio, com distensão muscular totalizando 10 dias de afastamento.

- M701 - transtornos dos tecidos moles relacionados com o uso, uso excessivo e pressão, registrado apenas em uma CAT, devido ao acidente ocorrido na sala de cortes, por um ajudante de frigorífico, causado por objeto ferramental, não especificado, causando luxação seguida de mialgia, totalizando sete dias de afastamento.

- M79.1 -mialgia foram registradas em 13 CATs, devidas aos acidentes ocorridos nas plataformas de aves vivas, evisceração, sala de cortes, embalagem, higienização, cozinha do refeitório, oficina de manutenção e fábrica de ração distribuídos entre o $1^{\circ}$ e $2^{\circ}$ turnos. Com as descrições seguidas de luxações, devido a posturas inadequadas, com comprometimento de múltiplas partes do corpo (coluna, membros superiores, inferiores e ombros), totalizando 84 dias de afastamento, distribuídos entre os acidentados. Postura inadequada no trabalho está inclusa na análise ergonômica do posto de trabalho, que contemplada pela NR-17 (BRASIL, 2006).

- W17 - outras quedas de um nível a outro, registradas em uma CAT, devida ao acidente ocorrido na plataforma de aves vivas $1^{\circ}$ turno como causa de queda da plataforma, apresentando escoriações com ferimentos superficiais, totalizando três dias de afastamento. As quedas em altura também devem ser analisadas durante a investigação dos acidentes para a identificação das possíveis falhas da segurança, que devem seguir a legislação preconizada pela NR-24 (contempla 
todo o layout, área física da empresa) e a NR-6 (contempla o uso de ${ }^{*} E P I$, principalmente no que diz respeito ao trabalho em alturas com utilização dos cintos de segurança) (BRASIL. MTE., 2002).

- W22 -impacto acidental ativo ou passivo causado por outros objetos, registradas em 11 CATs, devido aos acidentes causados nos setores de plataforma de aves vivas, expedição, embalagem, higienização, sala de cortes e rodovia. Com as descrições de preensão da mão em esteira de carregamento, preensão do pé em trava do rack de paletes, preensão do pulso em guincho de descarga de gaiola de aves, queda devido ao excesso de força exercido para empurrar caixas com produtos, lesão em mucosa ocular devido ao contato com sabão neutro, durante a limpeza da máquina, lesão com grampeadeira durante atividade de grampear pacotes de frango, polegar atingido por serra de disco e acidente dentro do ônibus de transporte da empresa com impacto sobre o vidro, causando cortes e lacerações com ferimentos contusos. A maioria dos acidentados apresentou lesões leves, não houve amputações e óbitos e totalizaram 44 dias de afastamento.

- T23- queimaduras e corrosão do punho e da mão, com 2 CATs, registradas devido aos acidentes ocorridos nos setores da plataforma de aves vivas, sala de cortes, com a descrição de queimaduras nos membros superiores, em razão do vapor oriundo da água quente utilizado no processo de escaldagem da ave (processo utilizada para retirar todas as penas das aves). O grau da queimadura não foi especificado na CAT, porém, pelas características do agente causador, pressupõe a queimadura de segundo grau, que tem como características flogísticas a formação de bolhas em virtude do processo de descontinuidade da 
derme. Outro fato relevante é o surgimento de vesículas (bolhas), na qual se deve ter todo cuidado higiênico para evitar a infecção. Porém, a atividade exercida por esses trabalhadores, que estão expostos a riscos biológicos, como conseqüência de contato com as aves vivas, torna-se potencializador. Surge então a preocupação com a atuação dos profissionais da saúde ocupacional nas empresas sob a ótica epidemiológica e prevencionista e não puramente curativa.

- Y28 -contato com objeto cortante, ou penetrante, intenção não determinada, registrada em apenas uma CAT, devido ao acidente que ocorreu na oficina de manutenção, atingindo o mecânico de manutenção, com a descrição de corte e laceração em perna esquerda devido à lixadeira.

Quanto ao agente causador dos AT, observou-se que em, 58 casos $(42,3 \%)$ os instrumentos de trabalho foram considerados objetos causadores dos AT, em 54 casos $(39,4 \%)$ foi o ambiente e em 23 casos $(16,8 \%)$ foram os mobiliários.

Diante das estatísticas dos agentes causadores, os instrumentos de trabalho mencionados são as facas utilizadas no processo de desossa das aves e multicortes exigidas pelos países para os quais a empresa exporta seus produtos. Como descrito anteriormente, os trabalhadores manipuladores de carne de aves executam atividades repetitivas, utilizando suas funções cognitivas e emocionais durante o abate, evisceração e corte das aves. A jornada de trabalho de oito horas diárias, com a organização do trabalho distribuída por turnos e atividade fragmentada e repetitiva, são alguns dos fatores de risco que predispõem á maior incidência de acidentes com esse tipo de agente causador.

Wisner (1994, p.79) reforça o conceito da intensificação da atividade cognitiva em atividades repetitivas; que ao realizar uma analogia aos estudos de 
Dejours (1987), observa-se que as atividades cognitivas, por ele denominadas de cargas psíquicas, estão intimamente ligadas às incertezas sobre a percepção ou sobre o significado das informações, perturbações quantitativas ou qualitativas do sono, relacionadas com os horários e com o conteúdo do trabalho. Todos esses fatores, quando não canalizados em atividades de lazer, intelectuais e afetivas levam ao sofrimento psíquico que pode somatizar, no indivíduo, perturbações orgânicas como descontrole hormonal, interferindo diretamente no funcionamento dos órgãos, como também alterações dos comportamentos emocionais, tais como: agressividade, angústia, idéias suicidas e fuga da realidade.

Como profissional da área da saúde do trabalhador, com atuação em diferentes empresas como enfermeiro do trabalho, a pesquisadora não encontrou programas de prevenção de acidentes de trabalho com enfoque na psicopatologia do trabalho, porém, considera que os fatores psicossociais podem afetar a saúde física e psicológica dos trabalhadores e pode ser fator predisponente a ocorrência de AT.

Segundo a Organização Internacional do Trabalho (ORGANIZACIÓN INTERNACIONAL DEL TRABAJO-OIT, 1984), os riscos psicossociais no trabalho consistem, por um lado, em interação entre o trabalho, seu ambiente, a satisfação no trabalho e as condições de sua organização e, por outro, em capacidades do trabalhador, suas necessidades, sua cultura e sua situação pessoal fora do trabalho; o que, afinal, através de percepções e experiências, pode influir na saúde, no rendimento e na satisfação no trabalho.

Os AT representam prejuízos pessoais e financeiros ao trabalhador, ás famílias, á sociedade e a empresa. Dentre os AT, $118(86,1 \%)$ foram responsáveis por afastamento do trabalhador de suas atividades laborais de até 15 dias e em 2 
(1,5\%) AT os trabalhadores acidentados permaneceram mais de 16 dias ausentes do trabalho. Em $17(12,4 \%)$ dos registros não havia informações a esse respeito.

Quando se considera a empresa, em sua totalidade, o cálculo do coeficiente de freqüência, para os anos 2004 e 2005, indica redução do risco de acidentes para o ano 2005, conforme indicado na Tabela 6.

Tabela 6 Coeficientes de freqüência de acidentes de trabalho na empresa nos anos 2004 e 2005

\begin{tabular}{cccc}
\hline \hline Período & $\begin{array}{c}\text { Número de } \\
\text { acidentes }\end{array}$ & $\begin{array}{c}\text { Horas-homens } \\
\text { trabalhadas }\end{array}$ & CF \\
\hline \hline 2004 & 86 & 1913074 & 44,95 \\
2005 & 51 & 2186241 & 23,33 \\
\hline \hline
\end{tabular}

De fato, a Tabela 6 mostra que o coeficiente de freqüência sofreu redução de $48,1 \%$, em 2005, quando comparado com o risco medido no ano anterior, de 44,95 acidentes por milhão de horas trabalhadas. Essa tendência decrescente pode ser também percebida quando se analisa a evolução temporal mensal desse coeficiente, apresentada na Figura 1. 


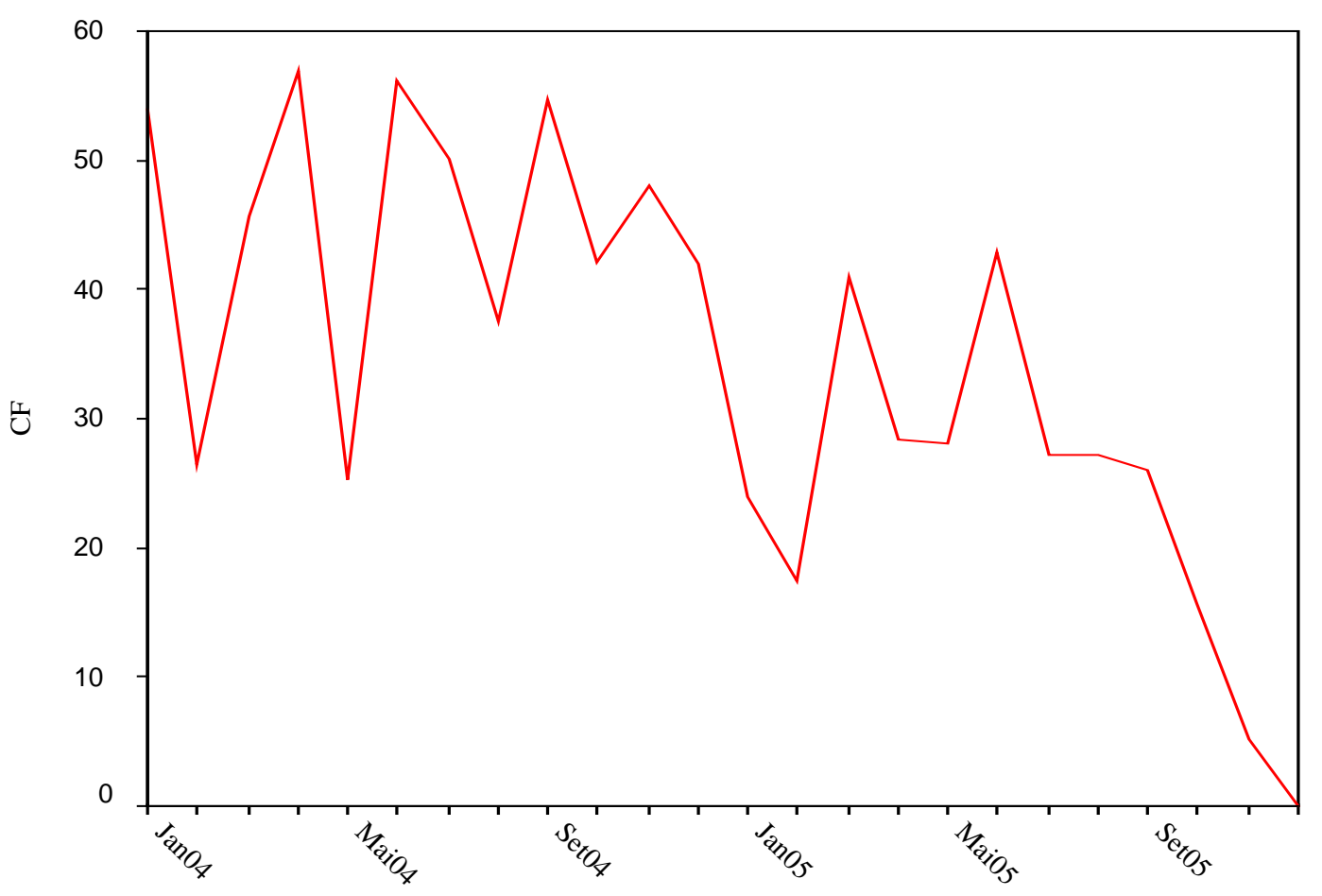

Figura 1. Evolução mensal dos coeficientes de freqüência de acidentes para a empresa, entre janeiro de 2004 e dezembro de 2005

Na Figura 1, vê-se que os meses de abril, junho e setembro de 2004 apresentaram os maiores coeficientes, respectivamente com 56, 93, 56, 19 e 54,64 acidentes por milhão de horas trabalhadas. Essa redução do risco de acidentalidade também decorre da redução do número de acidentes e do aumento do número de horas trabalhadas.

A Tabela 7 apresenta os coeficientes de freqüência para cada uma das Unidades componentes da indústria. 
Tabela 7. Coeficientes de freqüência de acidentes (CF) para as unidades componentes da empresa, nos anos 2004 e 2005

\begin{tabular}{lcc}
\hline \multicolumn{1}{c}{ Unidade } & CF (2004) & CF (2005) \\
\hline DEABA/aves & 45,54 & 19,36 \\
SEFAC/embutidos & 53,66 & 11,31 \\
SEINC/serviços auxiliares & 44,20 & 48,81 \\
BELVEDERE/granja e & 85,38 & 83,91 \\
incubatório & & \\
DERAC/fábrica de ração & 28,58 & 81,25 \\
Posto de vendas/ovos & 8,10 & 0,00 \\
\hline \hline
\end{tabular}

Observando-se a tabela acima, é possível destacar os seguintes pontos:

1. tanto em 2004 quanto em 2005, a unidade granja/incubatório (Belvedere) apresentou o maior indicador de risco ocupacional, com coeficiente de freqüência excedendo aquele as demais unidades; considerando o posto de vendas, que não registrou nenhum acidente em 2005, como unidade de referência, a razão de taxas para a unidade granja/incubatório, em 2004, foi de:

$$
R T_{2004}=\frac{C F_{\text {BELVEDERE }}}{C F_{P . V e n d a s}}=\frac{85,38}{8,10}=10,54
$$

Ou seja, em relação ao posto de vendas, o risco de acidentalidade na unidade granja/incubatório (Belvedere), em 2004, foi mais de 10 vezes superior;. 
2. excetuando-se a fábrica de ração e a unidade de serviços auxiliares, as demais unidades reduziram os indicadores de risco em 2005. No entanto, a granja apresentou a menor redução, permanecendo a unidade com elevados índices de acidentalidade, em relação às demais.

A redução do número de acidentes pode estar relacionada à aplicação do Treinamento no Local de Trabalho (TLT) realizado pela equipe de técnicos de segurança do trabalho da empresa, durante o ano 2005. No entanto, não se pode inferir sobre qual o real motivo dessa redução, uma vez que para tal, se faz necessário analisar quais as mudanças ocorridas no ambiente de trabalho, na produção, na organização do trabalho, entre outros aspectos. Esses resultados remetem a questionamentos a serem investigados em futuras pesquisas.

Os gráficos contidos nas duas figuras seguintes apresentam descrição mais detalhada da evolução temporal dos indicadores de risco nas unidades componentes. A propósito, vê-se, na Figura 2, que a Belvedere, que registrou o maior indicador de risco acumulado em 2004 e 2005, registrou elevadas taxas de acidentalidade, seguidas por meses sem acidentes de trabalho. Em 2004, foram registrados acidentes nessa unidade apenas nos meses de janeiro, agosto e setembro, com taxas, respectivamente, de 539,08, 259,74 e 252,08 acidentes por milhão de horas trabalhadas. Já, em 2005, os meses com acidentes, na Belvedere, foram março, junho e outubro, com taxas, respectivamente, de 512,69, 250,25 e 228,83. É preciso ressaltar que o número de horas trabalhadas na granja/incubatório é bem inferior às demais unidade. Comportamento semelhante, embora com valores de pico menos elevados e mais freqüentes, pode ser visto para a fábrica de ração. A Figura 2 ainda destaca a incidência contínua de acidentalidade no abatedouro de aves (DEABA), ao longo do período. 


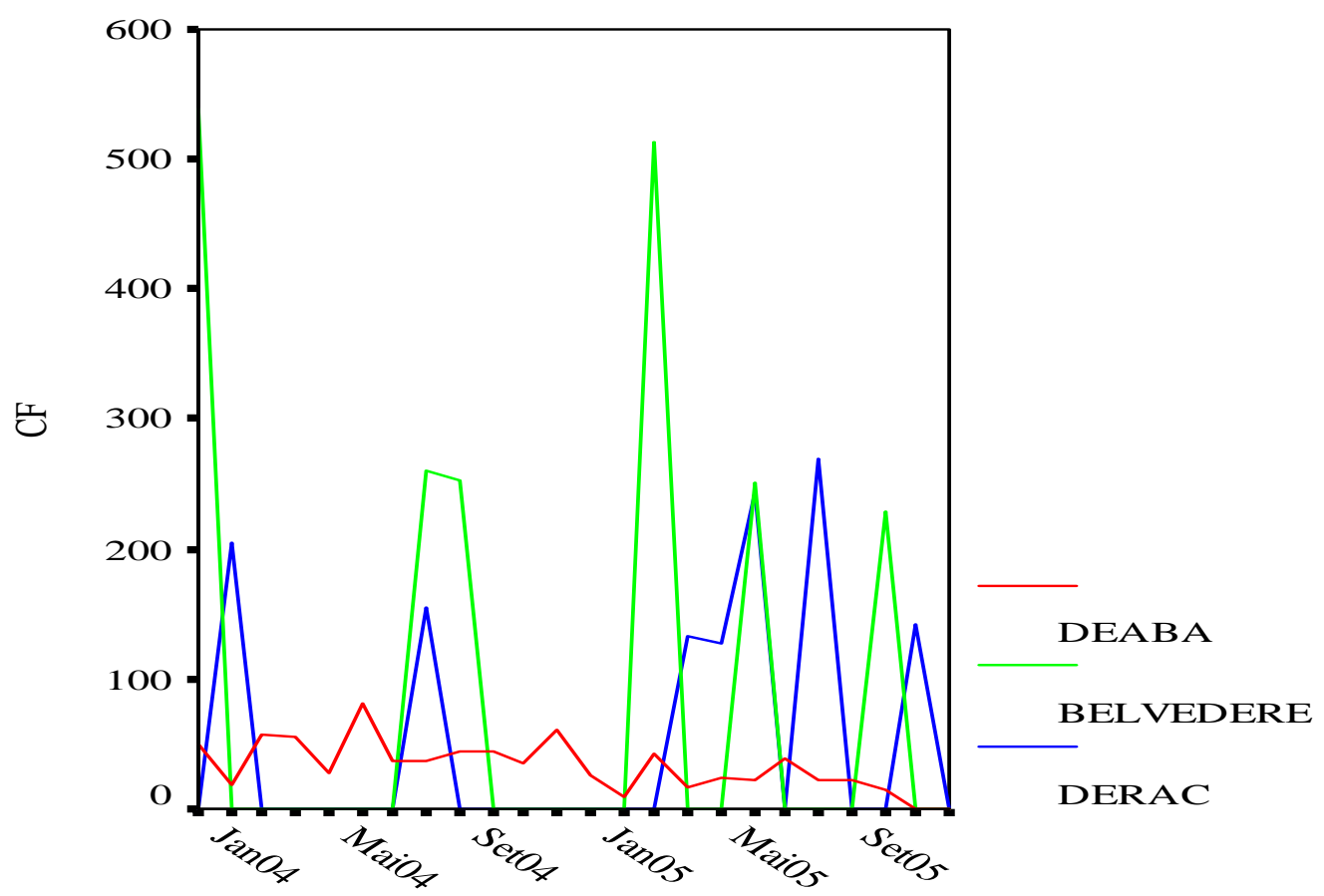

Figura 2. Evolução temporal dos coeficientes de freqüência de acidentes, por Unidade, de janeiro de 2004 a dezembro de $2005^{*}$

A Figura 3 apresenta a evolução mensal dos coeficientes de freqüência para as unidades restantes. O posto de vendas registrou apenas 1 acidente em julho de 2004 , apresentando taxa de 101,87 acidentes por milhão de horas trabalhadas. As unidades SEINC (serviços auxiliares) e SEMAT (embutidos) apresentam evolução semelhante, com alternância de meses com e sem acidentes. No entanto, a unidade de embutidos apresentou risco ocupacional decrescente em 2005, registrando acidentes apenas nos meses de fevereiro e junho.

*DEABA: Departamento de Abatedouro; BELVEDERE: Granja; DERAC: Departamento de Ração; SEFAC:Setor de Fabricação; SEAUX: Serviços Auxiliares; 


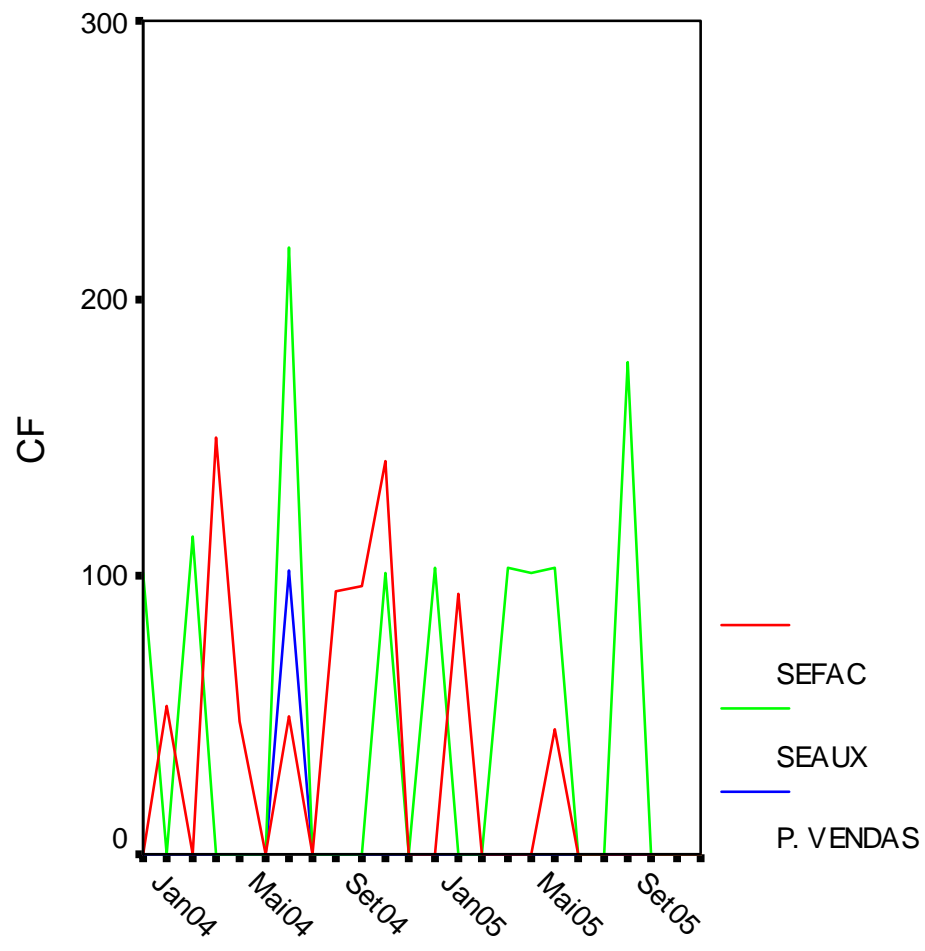

Figura 3. Evolução temporal dos coeficientes de freqüência de acidentes, por unidade, de janeiro de 2004 a dezembro de 2005 
A situação de trabalho analisada pela ocorrência de Acidente de Trabalho da indústria frigorífica estudada mostrou que, na empresa, durante o biênio 20042005, foram registrados 137 AT, dos quais 134 AT $(97,8 \%)$ foram acidentes típicos e $3(2,2 \%)$ acidentes de trajeto. Os AT foram sofridos por 135 trabalhadores que executam suas atividades laborais em diferentes unidades da empresa e que apresentaram as seguintes características: idade entre 18 e 73 anos, com maior prevalência entre 25 e 40 anos de idade com freqüência de 56 (41,5\%); trabalhadores do sexo masculino $108(80 \%)$, casados $59(43,7 \%)$ e apresentando média de salário mensal de $\mathrm{R} \$ 572,74$. A maioria dos trabalhadores acidentados exercia a ocupação de ajudante de abatedouro $(62,22 \%)$ e ajudante de serviços gerais $(9,6 \%)$ e a unidade de aves foi o local de trabalho onde os AT mais ocorreram, ou seja, 89 (65,7\%) indivíduos se acidentaram no referido local.

No entanto, quando calculado o coeficiente de risco de AT, tanto em 2004 quanto em 2005, a unidade granja/incubatório (Belvedere) apresentou o maior indicador de risco ocupacional, com coeficiente de freqüência excedendo aquele das demais unidades.

Constatou-se também que, excluindo a fábrica de ração e a unidade de serviços auxiliares, as demais unidades reduziram os indicadores de risco em 2005. No entanto, a granja/incubatório apresentou a menor redução, permanecendo a unidade com elevados índices de acidentalidade, em relação às demais.

Em relação ao tipo de AT sofrido, os acidentes típicos ocorreram com maior freqüência $134(97,8 \%)$ entre os trabalhadores, seguidos por apenas três acidentes de trajeto $(2,2 \%)$.

Do total de AT, 102 (74,5\%) ocasionaram afastamento dos sujeitos do trabalho e no turno matutino foi registrada a maior freqüência dos AT (65), 
correspondendo a $47,4 \%$ do total de AT.

Analisando o coeficiente de freqüência mensal dos acidentes, entre janeiro de 2004 e dezembro de 2005, constatou-se que os meses de abril, junho e setembro de 2004 apresentaram os maiores coeficientes, respectivamente, com 56, 93, 56,19 e 54,64 acidentes por milhão de horas trabalhadas. Em sua totalidade, o cálculo do coeficiente de freqüência, para os anos 2004 e 2005, indica redução do risco de acidentes para o ano 2005, onde os coeficientes de freqüência de ocorrência dos AT encontrados foram de 44,95 em 2004 e de 23,33 em 2005, sendo que o coeficiente de freqüência sofreu redução de 48,1 \%, em 2005, quando comparado com o risco medido no ano anterior.

As causas diagnósticas mais freqüente atribuídas ao AT foram (S00-S99) em 16,02\% dos casos, representadas por traumatismo superficial de cabeça, traumatismos do tornozelo e do pé, seguidas pelas doenças do sistema osteomuscular, (M00-M99), apresentando percentual de 10,95\%. Outras causas de traumatismos acidentais: exposição a forças mecânicas; outros riscos acidentais à respiração; exposição à corrente elétrica (W00-W99) ocorreram em 8,03\% dos casos. Ressalta-se que em $2,19 \%$ das CATs analisadas não havia registro da causa diagnóstica e essa falta de informação prejudica o real diagnóstico da situação acidentária na empresa.

Quanto ao agente causador dos AT, os instrumentos de trabalho representaram 42,3\% das ocorrências, o ambiente (39,4\%), os mobiliários 16,8\% e 1,5\% dos registros não continham essa informação.

Dentre os AT, $118(86,1 \%)$ foram responsáveis por afastamento do trabalhador de suas atividades laborais de até 15 dias e em 2 (1,5\%) AT os trabalhadores acidentados permaneceram mais de 16 dias ausentes do trabalho. Em 
$17(12,4 \%)$ dos registros não havia informações a esse respeito. Os custos para a empresa com os acidentes de trabalho, no biênio de 2004 -2005 foram de trinta e um reais $(R \$ 31,00)$ como valor mínimo e hum mil setecentos e noventa e um reais e cinqüenta centavos ( $R$ \$ 1791,50) como valor máximo, obtendo assim um total de vinte mil quatrocentos e vinte e sete reais e sessenta e sete centavos (R\$ 20,427,67). Embora o custo financeiro para a empresa não seja representativo, certamente os AT ocasionaram mudanças para o trabalhador acidentado, sua família, para os colegas de trabalho e para a produtividade da empresa, além do que o AT não pode ser encarado como algo natural, ele deve ser prevenido e evitado, pois é direto do cidadão ter adequadas condições de trabalho e é dever das empresas e do Estado assegurar-Ihe segurança no trabalho.

Os AT são considerados como agentes de redução das capacidades ao longo da vida, e muitas vezes mal avaliados, pois se trata de acontecimentos que têm, cada um deles, causas e conseqüências particulares. Os dados estatísticos globais permitem mensurar o tamanho do problema em relação aos efeitos dos acidentes sobre as funções fisiológicas, no entanto, os efeitos individuais causados no trabalhador são pouco valorizados.

Os profissionais de saúde podem contribuir para a prevenção de adoecimento e dos AT e o enfermeiro do trabalho deve atuar de maneira eficiente na promoção da saúde do trabalhador, através da realização de ações de vigilância epidemiológica e vigilância sanitária, ações de recuperação e a reabilitação dos trabalhadores, no entanto, suas ações devem estar principalmente voltadas para a melhoria das condições de trabalho, na organização humanizada do trabalho respeitando as características psicofisiológicas dos trabalhadores, oferecendo-lhes segurança para a execução do trabalho. 
ANTUNES LIMA, M.E. et.al. Lesões por esforços repetitivos -dimensões orgânicas e psico-sociais. Belo Horizonte: Health,1997.

ACGIH (American Conference of Governmental Industrial Hygienists), ABHO (Associação Brasileira de Higienistas Ocupacionais) (1999). TLVs (Limites de Exposição) e BEls (Índices Biológicos de Exposição)- São Paulo.

BEDRIKOW, BAUMECKER, BUSCHINELLI. Acidentes de Trabalho: Risco e Conseqüência. Ministério da Previdência Social 1996

BINDER, M.C., WLUDARSKI, S.L., ALMEIDA, I.M. Estudo da evolução os acidentes do trabalho.

BRASIL. Ministério da Agricultura, Anexo I-Regulamento Técnico da Inspeção Tecnológica e Higiênico-Sanitária de Carnes de Aves, Portaria $n^{\circ}$. 210 de 10/11/1998, publicada no D.O.U. de 26/11/98 seção 226; Disponível em http://www.agricultura.gov.br

BRASIL. Lei 8.213, de 24 de julho de 1991. Dispõe sobre os planos de benefícios da previdência social e dá providencias. Disponível em: http://www.trt02.gov.br/Geral/tribunal2/Legis/Leis/8213-91.html Acesso em: 27 de janeiro.2006.

BRASIL. Consolidação das Leis do Trabalho. Decreto-lei. Decreto-lei $n^{\circ} 5452$, de $1^{0}$ de maio de 1943. Aprova a consolidação das leis do trabalho. Lex: coletânea a de legislação. Edição Federal, São Paulo, v 7, 1943.

BRASIL. Constituição (1988). Constituição da República Federativa do Brasil. Brasília, DF: Senado, 1988.

BRASIL. Ministério da Fazenda. .Classificação Nacional das Atividades Econômicas.Disponível em : $\quad$ www.receita.fazenda.gov.br/pessoa juridica/CNAEFiscal/cnaef.htm. Acesso em : 12 de maio de 2006.

BRASIL. Ministério da Saúde do Brasil. Doenças Relacionadas ao Trabalho. Manual de procedimentos para os Serviços de Saúde. Brasília DF, 2001, pp.573

BRASIL. Ministério do Trabalho e do Emprego. Classificação Brasileira de Ocupações. Brasília. 2002b.

BRASIL. Ministério do Trabalho e Emprego. Segurança e saúde no trabalho: 
legislação.

Disponível

em:

http://www.mtb.gov.br/Temas/SegSau/Legislacao/Normas/Default.asp. Acesso em: 27 de jan de 2006.

BRASIL. Ministério da Previdência Social. Política Nacional de Segurança e Saúde do Trabalhador . Brasília- Novembro de 2004. Disponível em: http://www.mpas.gov.br. Acesso em: 27 de jan de 2006.

.BRASIL. Ministério do Trabalho e Emprego. Manual de Aplicação da Norma Regulamentadora $\mathrm{n}^{\circ}$. 17. 2002. Disponível em: http://www.mte.gov.br/temas/seg sau/publicações/conteúdo/106.pdf. Acesso em: 27 de fevereiro de 2006.

BRASIL Ministério do Trabalho Emprego. Medidas para Controle de Riscos Ocupacionais na Indústria de Abate e Processamento de Carnes. Proposta de Nota Técnica. 2004.

SEBRAE. Classificação das empresas de acordo com o número de funcionários.Disponível em : www.sebrae.com.br/br/osebrae/estatuto.asp. Acesso em : 12 de maio de 2006.

BORSOI, I.C.F. Acidente de trabalho, morte e fatalismo. Psicologia Social.v.17 n.1, p1, Porto Alegre jan/mar 2005.

CACCIAMALI, M.C; SANDOVAL, S.A.M; JOSÉ-SILVA, M.F. A busca pela promoção da saúde medidas preventivas nas negociações coletivas.In: CHAHAD, J.P \& CACCIAMALI, M.C. Mercado de trabalho no Brasil. Novas práticas trabalhistas, negociação coletiva e direitos fundamentais no trabalho. São Paulo: LTr, 2003, p 193-224.

CAMPBELL, D.: Health Hazards in Meatpacking industry. Occupational Medicine: State of the Art Reviews, 14(2):351-372, 1999.

CHECKOWAY, H., PEARCE, N., KRIEBEL, D.: Research Methods in Occupational Epidemiology. 2a . Ed, Oxford University Press, 2004.

COUTO, H.A. Como implantar ergonomia na empresa: a prática dos comitês de ergonomia. Belo Horizonte.Ergo, 2002.336p.

DEJOURS, C. WISNER, A, DANIELLOU, F. Uncertainty and anxiety in continuous process industries. In Noro. K. Occupational health in automated factory. London: Taylor and Francis, 1987.

FISHER, F.M. Absenteísmo e acidentes de trabalho entre trabalhadores em turnos de indústrias automobilísticas. Tese de Doutorada-Faculdade de Saúde Pública, São 
Paulo, 1984.

GALBRAITH, J.K. A cultura do contentamento, São Paulo, Pioneira, 1992.

GALLOIS, N. S. P.: Análise das Condições de Estresse e Conforto Térmico sob Baixas Temperaturas em Indústrias Frigoríficas de Santa Catarina. Dissertação (Mestrado) apresentada ao Programa de Pós-Graduação em Engenharia de Produção da Universidade Federal de Santa Catarina. Florianopolis, 2002

GIAMPAOLI, Eduardo (1985). Temperaturas Extremas. In: Riscos FísicosFundacentro, São Paulo.

GOLDSMITH, R (1989). Cold and work in the cold. In: Ecyclopédia of Occupational Health and Safety, International Labour office, Geneva, Switzerland, pp.504-507.

GRIEFAHN, Bárbara (2000). Limits of and possibilities to improve the IREQ cold stress model (ISO/TR 11079). A validation study in the field. In: Applied Ergonomics 31, Dortmuid, Germany, pp.423-431.

HALDER, N.M, (2001). Reumatology and the health of the work force. Artrhritis \& Rheumatism In: Official Journal of the American College of Reumatology. Atlanta, U.S.A, 44 (9).

HUMAN WRIGHTS WATCH: Blood, Sweat and Fear: Worker's Wrights in U.S. Meat and Poultry Plants. 2004.

INSTITUTO BRASILEIRO DE GEOGRAFIA E ESTATÍSTICA (IBGE). Comissão Nacional de Classificação - CONCLA. Disponível em: www.ibge.gov.br/conclal Acesso em: 12 de maio de 2006.

ISO/TR 11079 (1993). Evaluation of Cold Clothing Insulation. ISO.Geneva.

INTERNATIONAL LABOUR OFFICE, BUREAU FOR WORKERS. ACTIVITIES, OCCUPATIONAL SAFETY AND HEALTH BRANCH (ILO). Your Health and Safety and Work: Introducion to Occupational Health and Safety, Torino: International Labour Office, 1999. 
LIMA, R.C. VICTORA, C.G. DALLAGNOL, M.M. FACCHINI, L. A. \& FASSA, A. G. (1999). Percepção da exposição a cargas de trabalho e os acidentes de trabalho em Pelotas, RS. Revista de Saúde Pública, 33-137-146.

MANUAL da FUNDACENTRO, Riscos Físicos, 1991, p.49-51.

MALCHAIRE , J. Y.; ROUQUELE, N.; COCK, A.; PIETTE, S.; VERGRACHT, H.; CHIRON. Musculoskeletal complaints functional capacity, personality and psychosocial factors. Arc Occup. Environ Health, 2001, 549-557.

MARTARELLO,N.A.; MAGRINI, R.O. Condições de Trabalho na operações de prensas. Programa de Saúde dos Trabalhadores: A experiência da Zona Norte: Uma alternativa em Saúde Pública. São Paulo, 1989, pg.267.

MENDES, R. Patologia do Trabalho. Rio de Janeiro: Atheneu, 1995.

MINAYO-CARLOS, G.; COSTA-THEDIM, S.M.F. Incorporação das ciências sociais na produção de conhecimento sobre trabalho e saúde. Ciência \& Saúde Coletiva, 8(1): 125-136 2003.

MUROFUSE, N.T. Mudanças no trabalho e na vida de bancários ocasionadas por lesões por esforço repetitivo-L.E.R. Ribeirão Preto, 2000 p. 9 - 13 .Dissertação de Mestrado Escola de Enfermagem, Universidade de São Paulo.

NAVARRO, V.L.; ALESSI, N.P.; LIMA, M.G. A violência no trabalho e a saúde do trabalhador no contexto da reestruturação produtiva no Brasil. In: SILVA, J.F LIMA, R.B; ROSSO, S.D. Violência e trabalho no Brasil. Goiânia: editora UFG 2001, pg.242.

NICOLESCU, B. A evolução transdisciplinar a Universidade. Condição para o desenvolvimento sustentável, 1997. Apresentado no Congresso Internacional Que Universidade para o Amanhã ?, Locarno, Suíça de 30 de abril a 2 de maio de 1997.

OCCUPATION SAFETY AND HEALTH. IN: Marketing and Procurement, relatório elaborado para a agência européia para a saúde e segurança no trabalho em inglês 2000, ISBN 92-95007-01-8.

OCCUPATION SAFETY AND HEALTH Guidelines for Poultry Processing: Ergonomics for the Prevention of Musculoskeletal Disorders. 2004. 
ORGANIZACIÓN INTERNACIONAL DEL TRABAJO OIT-. Factores psicosociales em el trabajo Naturaleza, incidencia y prevención. Genebra: OIT, 1984.

ORGANIZAÇÃO MUNDIAL DA SAÚDE. Classificação estatística internacional de doenças e problemas relacionados à saúde CID-10. Tradução Centro Colaborador da OMS para Classificação de Doenças em Português (USP). 2d. São Paulo. Edusp, 1993, v1.

ORSO, P.J. Participação como Representante do PES. In: ANAIS: Seminário sobre LER-lesões por esforços repetitivos. Cascavel:Edumioeste, 1998. p19-20.

PASTORE, C. Custo do acidente do trabalho no Brasil. Brasília: (s.n.), 1999. Mimeografado.

PERSONIC, M. E, Taylor-Smith, K.: Profiles in Safety and Health: Occupational Hazards in Meatpacking. Monthly Labor Review, 112(1):3-9, 1989.

PORTO, M.F. S e FREITAS, C.M. Análise de Riscos Tecnológicos Ambientais: Perspectivas Para o campo da Saúde do Trabalhador. Cadernos de Saúde Pública, 13:59-72,1997.

UNITED STATES GOVERNMENT ACCOUNTABILITY Office (GAO): Safety in the Meat and Poultry Industry, while Improving, Could Be Further Strengthened. 2005.

SANTOS, U.P.; MARTARELLO, N.A.; CARMO, J.C.; COSTA, D.F. Intervenção nos ambientes de trabalho. Programa de Saúde dos Trabalhadores. A experiência da Zona Norte: Uma alternativa em Saúde Pública. São Paulo, 1999, pg.179.

SELIGMANN, S.E.; DÉLIO, A.A. \& SATO, L. A saúde na área operativa do metrô de São Paulo. Diesat São Paulo, Sindicato dos metroviários 1986, 319 pp.

SHLOSSER, E. The Chain Never Stop July- August 2001 Issue.

TOMADA, S. Safety and health of meat poultry and fish processing workers. Geneva: International Labour Organization, 2000 Disponível em: http://www.ilo.org/public/english/sector/papers/fishsafe. Acesso em : 24 maio 2005.

WISNER, A. A inteligência no trabalho. São Paulo: FUNDACENTRO, 1994. 191p.

WUNSCH, V.F. Reestruturação produtiva e acidentes de trabalho no Brasil: estrutura e tendências. Caderno Saúde Pública, Rio de Janeiro, 15(1):41-51, jan-mar,1999. 
ANEXO 


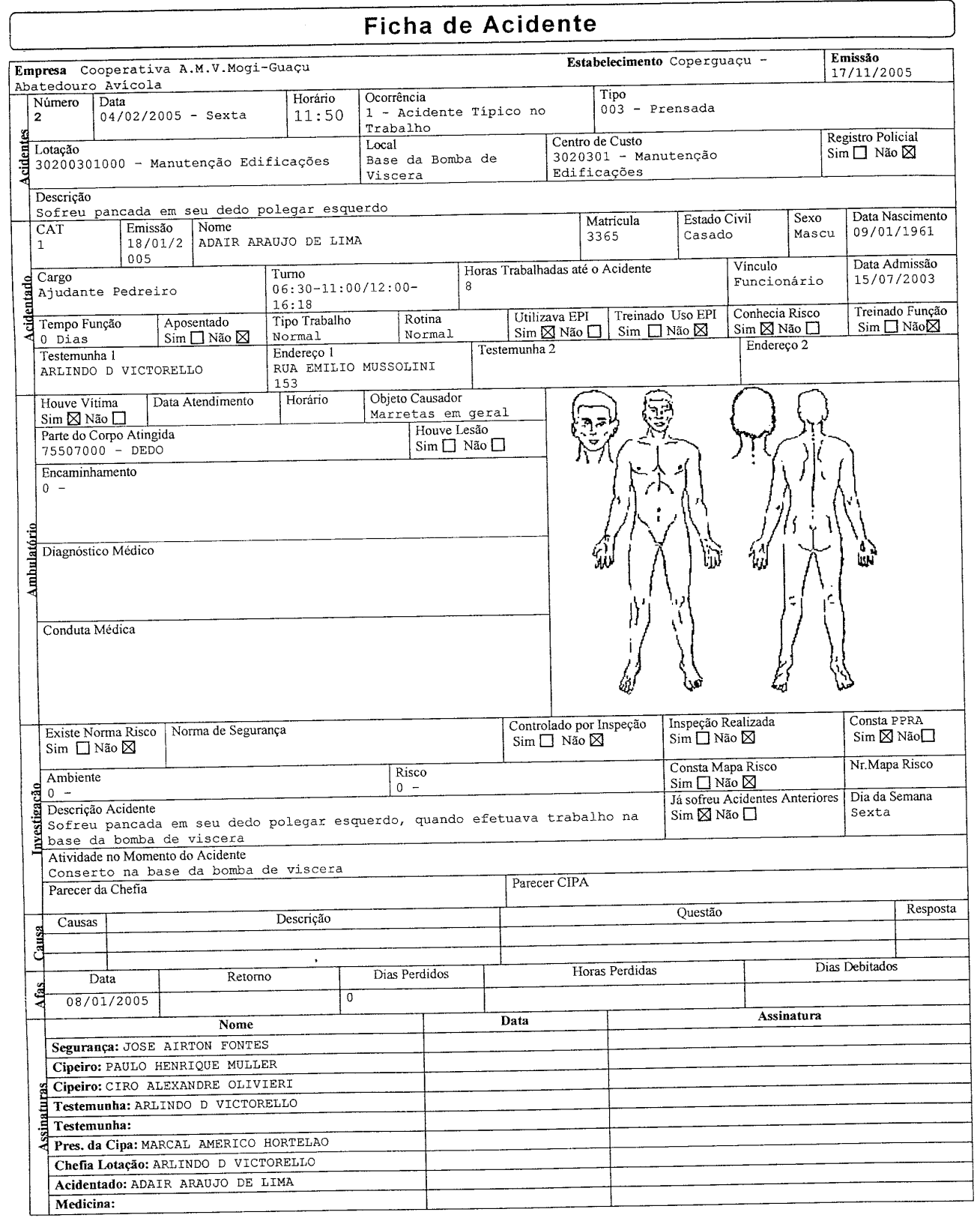

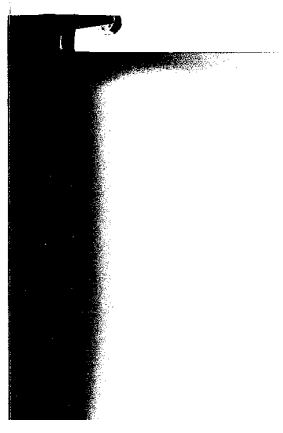




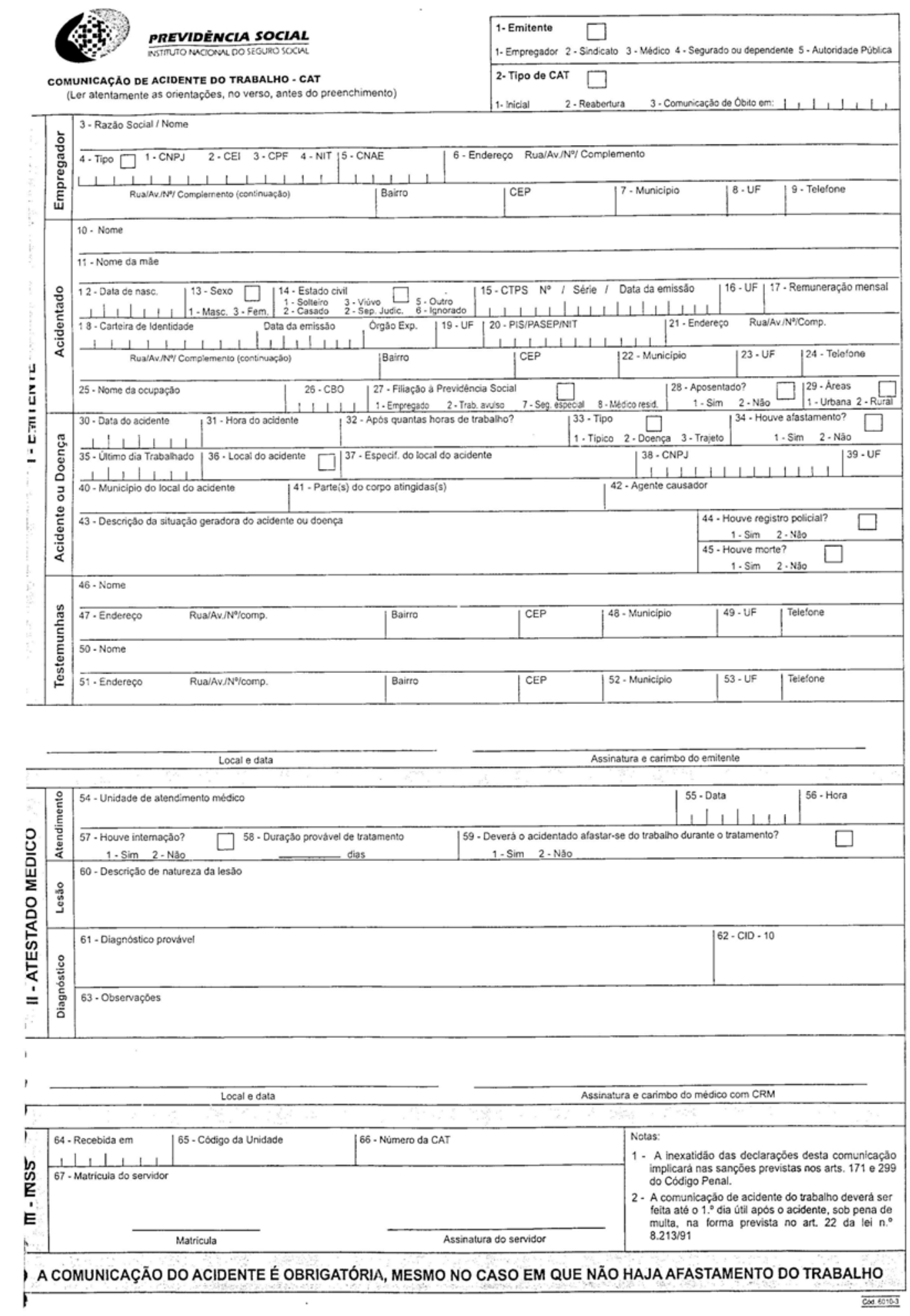


MINISTÉRIO DA SAÚdE

24. Comissão Nacional de Ética em Pesquisa - CONEP

PROJETO RECEBIDO NO CEP

Projeto de Pesquis

CAAE - 0705.0.153.000-05

Acidentes e Doencas rolacionadas ao trabalho em uma Indústria Frigorifica e Processamento de Ave

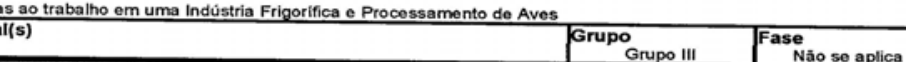
\begin{tabular}{|l|l}
\hline CPF & Pesquisador Responsável \\
\hline
\end{tabular}

\begin{tabular}{|l|l|l|l} 
Nano se aplica & \\
\hline
\end{tabular}

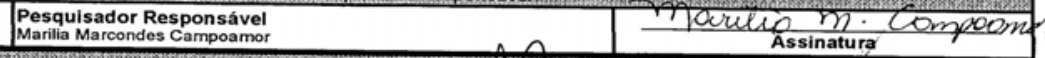

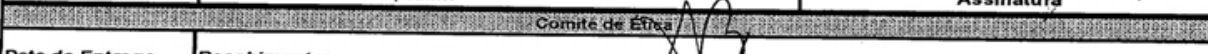
\begin{tabular}{c|l}
\hline $\begin{array}{c}\text { Data de Entrega } \\
\text { 29/11/2005 }\end{array}$ & Recebimento: \\
\hline
\end{tabular} (1) Wagnexaghatiat Buoel

Este documento deverá ser, obrigatoriamente, anexado ao Projeto de Pesquisa.

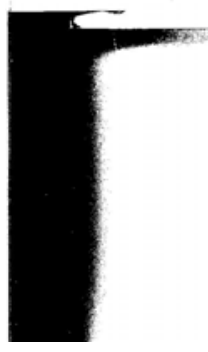



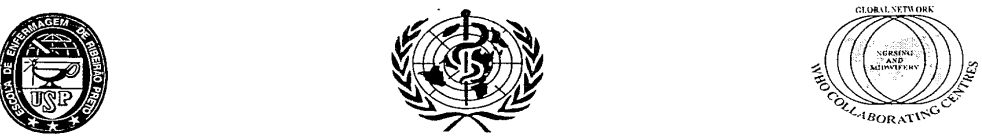

ESCOLA DE ENFERMAGEM DE RIBEIRÃO PRETO - UNIVERSIDADE DE SÃO PAULO CENTRO COLABORADOR DA ORGANIZAÇÃO MUNDIAL DA SAÚDE PARA

O DESENVOLVIMENTO DA PESQUISA EM ENFERMAGEM

Avenida Bandeirantes, 3900 - Campus Universitário - Ribeirão Preto - CEP 14040-902 - São Paulo - Brasil
FAX. 55 - 16 - 633-3271/55-16-630-2561 - TELEFONES: 55 - 16-633-0379/602-3382

COMITÊ DE ÉTICA EM PESQUISA DA EERP/USP

Of.CEP-EERP/USP - 0179/2005

Ribeirão Preto, 19 de dezembro de 2005.

Prezada Senhora,

Comunicamos que o projeto de pesquisa, abaixo especificado foi analisado e considerado APROVADO pelo Comitê de Ética em Pesquisa da Escola de Enfermagem de Ribeirão Preto da Universidade de São Paulo, em sua $\mathbf{8 2}^{\mathbf{a}}$ Reuniāo Ordinária, realizada em 15 de dezembro de 2005.

Protocolo: $\quad n^{\circ} 0626 / 2005$

Projeto: Acidentes de Trabalho em Indústria Frigorífica do Interior do Estado de São Paulo.

Pesquisadores: Maria Helena Palucci Marziale (Orientadora)

Marília Marcondes Campomar (Mestranda)

Em atendimento à Resolução 196/96, deverá ser encaminhado do CEP

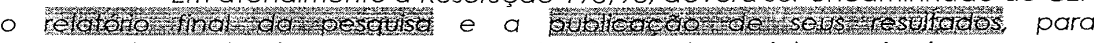
acompanhamento, bem como comunicada qualquer intercorrência ou a sua interrupção.

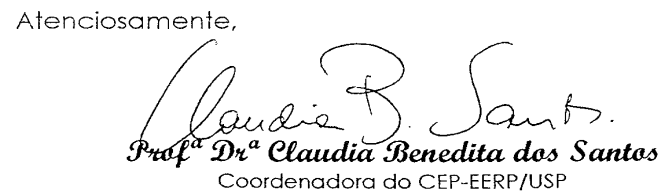

$11 \mathrm{~m}^{\mathrm{a}} \cdot \mathrm{Sr} \mathrm{r}^{\mathrm{a}}$

Profa. Dra. Maria Helena Palucci Marziale

Departamento de Enfermagem Geral e Especializada

Escola de Enfermagem de Ribeirão Preto-USP 